\title{
Aprendizaje tecnológico en empresas de software en México. Cuatro territorios locales: Guadalajara, Tijuana, Mexicali y Distrito Federal
}

\author{
Miguel Ángel Rivera,* Arturo Ranfla** y José Luis Bátiz***
}

\section{RESUMEN}

Se examinan algunos aspectos de la conformación de la industria de servicios de software en México, adoptando un enfoque territorial, circunscrito en la teoría del desarrollo tardío y del cambio institucional. Se subraya que el software es una industria nueva y su propagación a países de desarrollo tardío depende de la transmisión internacional de conocimiento tecnológico. La hipótesis se apoya en el concepto de ecosistema de software. Entre más denso es el ecosistema mayor es el mercado local y, potencialmente, las posibilidades de aprendizaje tecnológico. Se señala que los servicios de software se han desarrollado principalmente en las ciudades de Guadalajara y México, pero han surgido de una industria fragmentada, pues pese a su potencial (alta proporción de ingenieros en la plantilla laboral en empresas locales nuevas) está siendo crecientemente marginada por dos tipos de competidores: las empresas globales y lo que aquí se llama competidores "genéricos" provenientes de España y la India, principalmente.

Palabras clave: desarrollo local, industria de servicios de software, economía mexicana. Clasificación JEL: O14.

\begin{abstract}
Some aspects of the conformation of the industry of services of software in Mexico are examined here, adopting a territorial approach, framed in the theory of the late development and institutional change. It is emphasized that software is a new industry and its propagation to late comer countries depends on the international diffusion of technological knowledge. The hypothesis drew on the concept of software ecosystem. With a denser ecosystem the local and national market can support technological learning and firm formation. It is indicated that the services software have been developed mainly in the City of Guadalajara and the City of Mexico, but suffer of fragmentation. In spite of its potential (high proportion of engineers in the labor force in new local firms) this local industry is being increasingly marginalized by two types of competitors: by global companies and what it is called here "generic" competitors from Spain and India, mainly.

Key words: local development, industry of services of software, Mexican economy. Classification JEL: O14.

\footnotetext{
* Doctor en economía, Universidad Nacional Autónoma de México. mriver@servidor.unam.mx

*** Maestro en estudios de desarrollo global, Universidad Autónoma de Baja California. jose. batiz@uabc.edu.mx; josebatiz@ucla.edu
}

** Doctor en ciencias económicas, Universidad Autónoma de Baja California. aranfla@uabc.edu.mx
\end{abstract}




\section{INTRODUCCIÓN}

El presente artículo examina algunos aspectos de la conformación y dinámica de la industria de servicios de software en cuatro ciudades de México. El enfoque es territorial ya que el desarrollo de sector está asociado con importantes efectos de aglomeración. El enfoque territorial se enmarca en la teoría del desarrollo tardío y del cambio institucional.

La industria del software es de frontera, pero su desarrollo es característicamente global en tanto que se requiere fuerza laboral de varios niveles de calificación, que es generalmente escasa en los países industrializados. Lo anterior ha dado lugar a importantes flujos de conocimiento internacional a partir generalmente del outsourcing interempresa (subcontratación internacional), lo que explica el éxito logrado en varios países, como Irlanda, la India, China y Brasil, convertidos de underdogs a tigres (Arora y Gambardella, 2005). Pese a existir un importante potencial territorial, los logros en México se encuentran muy por debajo de los casos anteriores, lo que plantea un número importante de preguntas de investigación.

La estructura geoespacial, que hace posible la actual aceleración y ampliación de los flujos de conocimiento tecnológico, es parte de lo que aquí denominaremos nueva geografía o mosaico del capitalismo, componente del cambio mundial que toma forma a partir de fines de los años ochenta.

En el concepto sistémico de globalización o de nueva geografía del capitalismo, hay un trasfondo que implica fuertes controversias y discrepancias en interpretaciones en cuanto a la relación entre lo global y local. Aquí se adopta principalmente la propuesta de la escuela de California asociada con la obra de Scott Allen y Michael Storper, pero sobre todo se propone un nuevo enfoque para extender la conceptualización y discusión a las aglomeraciones territoriales en países tardíos, en los que identificamos dos modalidades. Una son los cluster (conglomerados) de aprendizaje localizados principalmente en países tardíos, que llamaremos tipo $\mathrm{A}^{1}$ (localizados sobre todo en Asia Pacífico, India y Brasil), en los cuales existe una interacción importante entre agentes internos y agentes globales para el aprendizaje y puede incluso haber autonomía de los primeros, para exten-

\footnotetext{
${ }^{1}$ Los países tardíos tipo A, cuyos casos más representativos son los tigres asiáticos, se caracterizan por poseer una matriz institucional que incentiva el aprendizaje social y organizacional (incluyendo el aprendizaje tecnológico); por ello, la inserción en la globalización ha implicado una rápida industrialización, con alto nivel de competitividad en industrias pertenecientes al nuevo patrón industrial (véase Rivera, 2009).
} 
der el ciclo de vida del producto mediante innovaciones de sistema y de organización, creando activos generadores de ganancias económicas internacionales.

Otra modalidad de conglomerado, también estudiada, pero menos celebrada, se encuentra en países tardíos tipo $\mathrm{B}$, de los cuales los más representativos son los de América Latina (quizás con excepción de Brasil), cuyo atraso relativo ha aumentado (medido como brecha internacional). ${ }^{2}$ En estos últimos, el aprendizaje efectuado por agentes endógenos, territorializados o no, es débil o intermitente y en consecuencia las empresas externas "expulsan" a las doméstico-locales (crowding out; Amsden, 2001). La pregunta de por qué difiere considerablemente la cantidad y calidad del aprendizaje social, organizacional y territorial entre ambas modalidades, no puede responderse diciendo que depende de los recursos de la empresa o del entorno en que opera ésta, ya que esto equivale a cambiar de forma la pregunta. En contraposición a las concepciones estructuralistas del desarrollo, basadas en una separación entre economía y política, la nueva teoría del desarrollo proporciona una hipótesis que abre perspectivas inéditas en el estudio de la situación de los países tardíos y de sus territorios locales.

La hipótesis que se formula aquí se apoya en el concepto de ecosistema de software (véase Messerschmitt y Szyperski, 2003). El origen de un ecosistema local puede combinar la acción de fuerzas globales y nacionales, cuya interacción define una trayectoria que es dependiente de su origen (dependencia del sendero). Lo relevante es la densidad del ecosistema, es decir, la participación de más agentes u organizaciones y su interrelación más estrecha para producir spillovers (desbordamientos). La densidad define los desbordamientos potenciales, la amplitud del mercado local y las posibilidades de aprendizaje y de absorción de flujos externos de información y conocimiento. Eventualmente, los agentes más avanzados del ecosistema podrán convertir la acumulación de capacidades tecnológicas en activos competitivos internacionalmente; empero, puede suceder que este paso se retarde o no se produzca y los agentes que avancen competitivamente sean extranjeros (no domésticos) radicados territorialmente (locales). El mercado que surge del poblamiento será encabezado y aprovechado primero por las empresas globales propietarias de plataformas (Microsoft, Oracle, etcétera), cuyos posibles desbordamientos pueden abrir espacio a empresas locales, e ini-

\footnotetext{
${ }^{2}$ La brecha internacional se mide como el porcentaje que representa el PIB per cápita del país tardío en comparación con el del país líder (Estados Unidos). Véase la metodología en Hikino y Amsden, 1998; Wilkie y Ray (2004) hacen una comparación entre países latinoamericanos y Estados Unidos, tomando los datos de Maddison. En Rivera (2009a) se mide la brecha internacional en países tardíos A y B.
} 
ciar el aprendizaje tecnológico, lo cual depende de la interacción de los factores arriba indicados.

Las cuatro ciudades de México en las que se enfocó la actividad de campo representan escaños en la constitución del ecosistema. En el escaño más bajo Mexicali, con cerca de un millón de habitantes, no posee propiamente un parque de empresas locales de servicios de software, aunque tiene potencial para un despegue en función del avance relativo de su sistema educativo (véase Estrella y Ranfla, 2007); la situación característica en una ciudad como Mexicali es que las empresas de mayor tamaño, oficinas de gobierno y universidades, utilizan software empaquetado, con contratos de servicios o adaptaciones propias. En seguida Tijuana, con aproximadamente 1.5 millones de habitantes y la segunda mayor concentración de empresas "maquiladoras" (outsourcing intraempresa) existente en México posee, en tanto una ciudad especializada en industria maquiladora de exportación (véase Hualde y Gomis, 2009, Hualde y Mochi, 2008), una aglomeración significativa de micro y pequeñas empresas, en algunos casos vinculadas con el mercado de Estados Unidos, con aprendizaje tecnológico y competitividad limitada en nichos.

En tercer lugar puede ubicarse a Guadalajara, cuya población (incluyendo municipios colindantes) alcanza los 3 millones de habitantes, con la ventaja de ser un centro mundial no sólo de ensamble sino de fabricación de algunos componentes para equipo de cómputo de telecomunicaciones y semiconductores, pero con una organización empresarial diferente de la centrada en Tijuana; en la industria electrónica asentada en Guadalajara las empresas líderes, comúnmente denominadas original equipment manufacturing (OEM) u original brand manufacturing (OBM), comandan cadenas de proveedores de diferente jerarquía (véase Dussel, 1994, y Palacios, 2003); los desbordamientos de esta estructura empresarial más la demanda de servicios de software, incluyendo el de tipo embebido o integrado al hardware, dio lugar a inicios de la década de 2000 a una floreciente industria, formada principalmente por micro, pequeñas y medianas empresas, varias de ellas internacionalmente competitivas. Como hipótesis, estamos hablando de una mayor densidad del ecosistema y un aumento en la complejidad de la organización empresarial local, que se ha traducido en la aparición y proliferación de lo que denominamos empresas científicas, poniendo de manifiesto una nueva vía de aprendizaje tecnológico local.

Finalmente, la ciudad de México presenta una macroconcentración urbana y en términos absolutos es mayor la densidad de su ecosistema de software, por razones obvias: el número y tamaño de sus centros de educación superior, 
oficinas de gobierno, parque empresarial, etcétera. No obstante, aunque los datos son insuficientes, el tamaño relativo del ecosistema de la ciudad de México es menor al de Guadalajara. El directorio de la Asociación Mexicana de Tecnologías de la Información (AMITI) registra 64 empresas en ese subsector; el Instituto Jalisciense de Tecnologías de la Información, A. C (Ijalti) tiene concentradas en el llamado cluster de software a 33 empresas, pero según estimaciones de sus directivos, en Jalisco a fines de 2009 existían cerca de 350 empresas en la localidad y aproximadamente 600 empresas en el estado. ${ }^{3}$ En la ciudad de México no tenemos estimaciones del número total de empresas, pero la información fragmentaria indica que es mayor que el de Guadalajara, al igual que el número de empresas científicas, según se anticipa en la hipótesis. Sin embargo, en el Distrito Federal el tamaño del ecosistema es menor en términos relativos.

Empero, al igual que en la ciudad de México, en Guadalajara el sector de servicios de software se encuentra fragmentado y las entidades públicas o privadas avanzadas que pueden articular a los pequeños proveedores, como las empresas concentradoras, han avanzado muy limitadamente y ha surgido un tercer actor que ejerce un efecto desintegrador del núcleo endógeno. Se trata de agentes que llamaremos "globales genéricos" (Tata Consulting, Perot Services, Hispanic Teleservices, etcétera) que efectúan outsourcing interempresa. El freno al desarrollo del conglomerado (cluster) en ambas ciudades se origina en factores institucionales nacionales, más que locales, y tiene su talón de Aquiles en el sistema de formación profesional y en la insuficiencia de apoyo estratégico a la empresa local. La política pública en los 20 años pasados ha tendido a desestimar la importancia del núcleo endógeno a favor del apoyo indiscriminado hacia la actividad empresarial en general, en tanto pueda propiciar la creación de empleos y el aumento de las exportaciones. En la práctica, aunque existen iniciativas sectoriales con orientación técnica o formalmente endógena, como el Prosoft, la política de apoyo indiscriminado a la empresa favorece a las de mayor poder de "negociación o representación", entre ellas las extranjeras. Retomaremos el punto más adelante al analizar los resultados de la entrevistas a empresas.

En síntesis, la hipótesis de investigación se puede explicitar así: en México se han conformado dos ecosistemas de software cuyo grado de densidad es lo suficientemente alto como para sostener una industria especializada como capa-

\footnotetext{
${ }^{3}$ Se trata de cifras aproximadas que indican que aunque el ecosistema es más denso en el Distrito Federal, Guadalajara tiene un mayor número relativo de empresas locales (en relación con el tamaño de la población).
} 
cidad competitiva internacional, un escaño inferior a la de Montevideo, por ejemplo. La existencia de lo que denominamos "empresas científicas" es indicativa de este avance. Las empresas científicas predominan en los dos mayores ecosistemas, como se probará con un modelo multivariado.

Sin embargo, el marco institucional es adverso a la consolidación de la empresa doméstico-local, debilitando los esfuerzos endógenos que han emergido de manera más o menos autónoma; el resultado es que el avance del sector ha sido accidentado, con su potencial contrarrestado por esos dos órdenes de factores. En la discusión de ese problema, la atención no puede centrarse puramente en los factores estratégicos, ya que la capacidad de alterar la política pública es limitada frente a factores institucionales que están definidos por elementos de profundidad estructural.

La investigación de campo empezó en Guadalajara en 2005 identificando a las start-up, como Asci y Mixbal, y a agentes nodales del aprendizaje organizacional, como el Cinvestav-Guadalajara) ${ }^{4}$ y el Centro de Tecnología de Semiconductores. La investigación directa siguió en 2006-2007 en el llamado cluster de Tijuana-ITBaja, gracias a la ayuda de Alfredo Hualde, quien nos proporcionó el directorio de empresas. En Tijuana y Mexicali la investigación llevada a cabo entre fines de 2008, 2009 y 2010 estuvo a cargo de Arturo Ranfla y José Bátiz de la UABC, campus Mexicali. La investigación en Guadalajara y el Distrito Federal estuvo a cargo de un equipo coordinado por Miguel Ángel Rivera Ríos, que concluyó su labor en agosto de $2010 .{ }^{5}$ El apoyo del Instituto de Ciencia y Tecnología del Distrito Federal (ICT-DF) nos facilitó el acceso al directorio de la AMITI, a partir del cual se organizaron las entrevistas estructuradas. Conacyt y el Programa de Proyectos de Investigación e Innovación Tecnológica de la UNAM brindaron recursos para las actividades de campo, seminarios y material de trabajo. Los datos extraídos de la encuesta se procesaron para probar el aumento de complejidad de la empresa local. La aparición de un nuevo tipo de competidores, los globales genéricos, tiene un grado de corroboración menor que surge de las mismas entrevistas, documentos oficiales que describen la estrategia

\footnotetext{
${ }^{4}$ El Centro de Investigaciones y Estudios Avanzados del Instituto Politécnico Nacional-Guadalajara fue el creador, en asociación con IBM, del Centro de Tecnología de Semiconductores, que funciona actualmente como una incubadora de empresas (véase Montiel, 2009).

${ }^{5}$ En las diferentes etapas de la investigación de campo participaron los siguientes pasantes de la Facultad de Economía de la UNAM: Víctor Montiel, Jessica Carpinteiro, Nancy Mena, Samuel Romo Cervantes, Anuar Sucar, Quetzal Méndez Bello, Carlos López Loyo y Dennise Aranda. Nuestro reconocimiento por su entusiasta apoyo.
} 
de gobierno e información periodística. Obviamente este último aspecto requiere mayor estudio de campo.

La exposición se organiza como sigue. En la sección I se presenta el marco teórico, dividido en: 1) la denominada nueva geografía del capitalismo; 2) el desarrollo tardío en un marco territorial, y 3) las aportaciones de la teoría del cambio institucional aplicada al desarrollo tardío, útiles para el estudio del proceso nacional y local. En la sección II se presenta la industria del software como eje del nuevo patrón industrial actual, en tanto que la sección III aborda el tema de los servicios de software en México. Por último, la sección IV presenta la metodología de tratamiento de datos, los resultados del trabajo de campo y la corroboración de la hipótesis.

El presente documento, en la forma en que está organizado y expuesto tiene limitaciones que debe tener en cuenta el lector. Se propone un marco teórico alternativo, pero por limitaciones de espacio está presentado de manera esquemática. El objetivo no es llegar a conclusiones definitivas, sino abrir una nueva perspectiva en una discusión que requiere un enfoque conjunto y obviamente mayor trabajo colectivo.

\section{MARCO TEÓRICO}

\section{La nueva geografía del capitalismo}

Como ha sido subrayado por varios autores, además de Scott (1998 y 2001), Storper (1997), Held et al. (2000) y Dabat (2002), la nueva estructura geoespacial que emerge presenta cuatro aspectos:

i) Global. Constituido en lo económico por cadenas o redes de actividad (productiva, financiera, comercial), escasamente reguladas por el sistema internacional de estados y que traspasan las fronteras nacionales.

ii) Plurinacional. Representado por entidades con diferente grado de cohesión, tales como la Unión Europa, el TLCAN, Mercosur, el ASEAN.

iii) Nacional. Pese que los gobiernos han perdido el control exclusivo del territorio y compiten contra poderosos agentes no territoriales, sigue siendo el actor central de la nueva geografía del capitalismo.

iv) Local o regional. Posee el potencial de emerger o resurgir como la articulación más dinámica de esta nueva geografía. 
La interrelación entre estos cuatro ámbitos la capta el concepto de regiones urbano-globales propuesta por Scott (1988 y 2001). El eje es un área macrometropolitana o un traslape de centros urbanos (conurbanizaciones) con una área circundante, hinterland, de extensión variable, que por lo general traspasa las fronteras nacionales (Scott, et al., 2001). El mosaico de la geografía global está constituido por una variedad de regiones urbanas globales de diferente nivel de desarrollo (1998).

Los nódulos dominantes de las regiones urbano-globales son los cluster innovativos. La tendencia a la aglomeración de las actividades de innovación se asoció con la incidencia de factores relativamente inmóviles, como el conocimiento, los arreglos institucionales y las formas específicas de organización productiva (Brechi y Malerba, 2001). El contraargumento de Krugman (1998) de que los flujos de conocimiento no tienden a anclarse geográficamente, incentivó el debate y la investigación. Es aquí donde resulta relevante la aportación de Storper (1997).

Ese autor argumenta que el nuevo contexto histórico, o sea el pasaje a la producción flexible, creó una fuerte incertidumbre. Las grandes corporaciones enfrentaron esa incertidumbre por medio de la desintegración (o sea, la especialización vertical), sobre todo para minimizar la exposición al exceso de capacidad, para maximizar los beneficios de la especialización en las actividades centrales y para minimizar los riesgos de amarre tecnológico (Storper, 1997). Pero la desintegración vertical eleva los costos de transacción de las relaciones productoinsumo, en especial cuando existen mayores distancias geográficas. La situación se agudiza cuando las transacciones involucran conocimiento tácito, o cuando se requiere un ingrediente de confianza o relación directa (Storper, 1997). La aglomeración geográfica de las empresas es una respuesta a esas nuevas exigencias. La proximidad de las empresas permite captar las externalidades positivas de la producción de conocimiento; a la par, la aglomeración permite minimizar los costos de transacción que derivan de la desintegración vertical.

Una vez establecida la aglomeración, se generan dinámicas endógenas de conocimiento y desarrollo tecnológico gracias a las transacciones de información y a la realimentación de los flujos de conocimiento. Denominaremos a esa condición, cuando consideremos la opinión de otros autores, propiedad intrínseca del territorio. El debate es la amplitud que se les asigna y si se sustentan con independencia de la economía nacional. Igualmente, si esa propiedad emerge en un territorio local de un país tardío B, aspecto en el que Fernández (2008) y Fernandez y Vigil (2007) centran la discusión. 
Scott (1998, pp. 86-90) formuló un modelo simple, con los mismos dos vectores (externalidades y costos de transacción) para estimar la tendencia a la aglomeración y su modalidad con dos límites (la entropía, máxima aglomeración). Maneja cuatro posibilidades: $i$ ) bajos costos de transacción-bajas externalidades (máxima dispersión o entropía); ii) costos de transacción heterogéneos (o altos)-bajas externalidades (dispersión de locación aleatoria o tendencia a privilegiar el acceso al mercado final); iii) bajos costos de transacción-altas externalidades (aglomeraciones pequeños, pero interconectados a distancia); costos de transacción heterogéneos-altas externalidades (aglomeraciones con fuerte cohesión, que al tener conexiones a distancia pueden convertirse en aglomeraciones gigantes), y $i v$ ) altos costos de transacción-altas externalidades (aglomerados pequeños pero desconectados).

\section{Problemas para el estudio del desarrollo tardío en un marco territorial}

Antes del corte histórico que significó el ascenso de la integración global de la producción propia de la nueva geografía, los países de América Latina, al igual que otras áreas atrasadas del mundo, tenían una historia de aglomeración de actividad industrial en localidades dispersas en la economía nacional (véase Bell y Albu, 1999, para una revisión crítica de la bibliografía dedicada a su estudio). En esas aglomeraciones de la era de la economía sustitutiva eran comunes, lo que Schmitz (1999) denominó artesanales, con escaso dinamismo y limitada capacidad de aprendizaje y competitividad. A partir de los años ochenta, en varios países atrasados, como Pakistán, India, Brasil y Colombia, entre otros, emergieron aglomeraciones orientadas a la exportación de productos intensivos en trabajo, con importante heterogeneidad de empresas.

La apertura a fuerzas competitivas globales produjo una desaparición generalizada de empresas, una decadencia o rehabilitación local y la aparición de nuevos actores empresariales intentando acoplarse a la nueva lógica competitiva. El caso de México es especialmente complejo, ya que al lado de los cluster reestructurados, como el del calzado en Guadalajara y León, se añaden las aglomeraciones de plantas que procesan para la exportación (autopartes, electrónicos y confecciones), con fuertes procesos de crowding out (véase Lara y Carrillo, 2003; Estrella y Ranfla, 2007; Bátiz, 2006).

Para entender la nueva realidad tuvieron que reformularse los viejos enfoques analíticos. El que adquirió mayor prominencia fue el de cluster, inspirado en Porter (1991), con influencia europea, en cierto modo importado de la boyante 
bibliografía metropolitana (véase una clasificación en Fernández y Vigil, 2007). Fue determinante en tales enfoques la idea de que en el nuevo contexto global y los procesos políticos concomitantes se perfilaba una nueva modalidad de desarrollo, surgida de la tradición centralista, que posibilitaba la liberación del potencial de actores, instituciones y capacidades locales. Posiblemente los trabajos de Vázquez Barquero (1999) de desarrollo endógeno "espontáneo", adoptados con entusiasmo por estudiosos latinoamericanos, sean el mejor ejemplo de este enfoque.

Representando un avance en el estudio de la realidad de nuestros países en el contexto de los cambios actuales, los nuevos enfoques territoriales presentan una diversidad de problemas que Fernández y otros autores llaman fallas de origen, producto de la transposición de conceptos. Siguiendo a Fernández (2008 y 2010) y Fernández y Vigil (2007) retomaremos tres de las cuatro fallas de origen discutidas por estos autores. Una primera falla se encuentra en la ambigüedad del concepto de lo que denominaremos propiedades intrínsecas del territorio (la disposición a cooperar e incluso a innovar por la radicación territorial), que posibilita diversidad de interpretaciones específicas, refractaria a las generalizaciones teóricas, lo cual explica la abundancia de estudios de caso y la ausencia de tratamientos integrados o de conjunto, según señalan. Una segunda falla de origen se ubica en el tratamiento de la unidad territorial local como entidad aislada, desvinculada de los marcos macrorregionales. Una tercera radica en la fuerte connotación normativa, a partir de la cual esos nodos territoriales deben verse como territorios locales que comparten los mismos problemas que el país atrasado en el que se ubican y no como extensiones de aglomeraciones innovativas. Predomina en consecuencia su definición como comunidades dinámicas per se (Fernández y Vigil (2007).

Diversos estudios de caso relativamente recientes efectuados en México presentan algunas de estas características de idealización. La mayoría brindan abundante información, pero dejan abierta una diversidad de preguntas en cuanto a la concepción del proceso de desarrollo a escala nacional, la relación entre lo local y lo nacional y las opciones estratégicas. Lo anterior amerita un replanteamiento que retome las aportaciones más valiosas de esa corriente de estudios, la crítica a las mismas, y las enmarque en la bibliografía vinculada con el desarrollo tardío a la que se hizo referencia con anterioridad.

El primer paso debe privilegiar la visión de conjunto, caracterizando el marco institucional que prevalece en el país y cómo conduce al aprendizaje social y a la innovación, tomando también de Fernández y otros autores afines la 
aplicación del análisis multiescalar y transescalar. A partir de esa aproximación es posible definir la modalidad de inserción a la economía global en general y a las cadenas productivas globales en particular, unificando localidad y nación. La definición del marco institucional puede llevar, a partir de una derivación de escalas, como propone Fernández (2010), al concepto de núcleo endógeno, en el sentido de debilitamiento o fortalecimiento del mismo ante los procesos de reinserción internacional.

Este ejercicio desembocará en una nueva visión de los nódulos de actividad territorial en México y de la dinámica local, como antesala al estudio de la industria del software. Evidentemente dentro de los marcos limitados de este estudio sólo es posible efectuar un esbozo del marco teórico-analítico que se describe arriba. No obstante, aun con las limitaciones propias de una aproximación general y tentativa, esta propuesta pretende llamar la atención sobre problemas que requieren una discusión unificadora y debidamente enmarcada dentro de una concepción conjunta del desarrollo, en la que se reconozca la importancia del territorio y de la estrategia. Nos centraremos ahora en la influencia de la matriz institucional.

\section{Marco institucional: la trampa del atraso y el cambio de trayectoria}

Las limitaciones al desarrollo nacional y local en los países tardíos tipo B están vinculadas a un bloque estructural de intereses político-institucionales que propenden a ser adversos al aprendizaje social; de haber aprendizaje social, condición crítica del desarrollo, tenderían a cambiar las reglas del "juego" y desarticular ese bloque de intereses. La incidencia adversa en el aprendizaje social no es reversible a partir de medidas de políticas superficiales, como las llaman Hoff y Stiglitz (2004), debido a que está radicada en la arquitectura institucional. Ese bloque estructural de intereses y fuerzas que gozan de alta representación política acapara el acceso a los recursos y actividades más rentables, entre ellas el crédito. North, Wallis y Weingast (2009) denominan a esa configuración de fuerzas políticas, sociales y capacidades económicas, Estado natural (o básicamente lo que Evans, 1995, define como "Estado depredador"). ${ }^{6}$ La pregunta crítica es

\footnotetext{
${ }^{6}$ El Estado conserva su carácter depredador aun cuando se den procesos de privatización y desregulación (reforma neoliberal), ya que es y puede ser utilizado como instrumento faccioso para acaparar riqueza a favor de una facción a partir del atributo de definir los derechos de propiedad. De allí que los monopolios públicos frecuentemente se hayan convertido en monopolios privados débilmente regulados (véase al respecto Hoff y Stiglitz, 2004).
} 
cómo se rompe el círculo vicioso producido por ese bloqueo o retardo. Aun cuando hay diferencias históricas y nacionales, compatibles con la idea de diversidad de capitalismos (véase Hall y Soskice, 2001), Hoff y Stiglitz (2004) formulan la hipótesis de que se requiere un choque endógeno o exógeno para cambiar el funcionamiento de la sociedad del tipo B, desarticulando ese bloque, para detonar el aprendizaje social y organizativo.

Los científicos sociales, salvo excepciones como Evans (1995), han evadido el problema bajo el amparo del paradigma que Hoff y Stiglitz llaman desarrollo racional, que supone que el Estado se convierte necesariamente en una poderosa fuerza que conduce hacia el aprendizaje. Ese Estado conductivo o desarrollista ubicuo está formulado como objeto teórico e histórico en libros como el de Atul Kohli (2004) de la universidad de Princeton. En contraposición a esa tesis y en la línea de North y la nueva teoría del desarrollo, aquí se sostiene que en los casos de éxito, entre ellos los tardíos, las condiciones originarias siempre fueron adversas, por lo que la detonación del aprendizaje colectivo implicó un cambio de trayectoria producida frecuentemente por una conmoción. Las intervenciones "a profundidad" (Hoff y Stiglitz, 2004), es decir, las que afectan la dinámica del proceso político podrían romper el círculo vicioso, aunque no de manera inevitable. ${ }^{7}$

En América Latina, las crisis sucesivas asociadas con el agotamiento cíclico de ganancias territoriales, o crisis fiscales, abrieron fisuras en el Estado depredador, pero dada la combinación de varios factores, como regla se descontinuó la configuración de una nueva matriz institucional; entre éstos están: $i$ ) fallas intrínsecas de la acción colectiva, endémicas en sociedades atrasadas, particularmente cuando las actividades decisivas para el desarrollo tienen externalidades positivas; ii) la transmisión intergeneracional de los factores sociales de exclusión que implican una forma de dependencia del sendero (las familias pobres transmiten a sus descendientes la matriz cultural de la pobreza); iii) la incertidumbre asociada a mayores costos de transacción por reformas en los derechos de propiedad que, aunque puedan elevar la ganancia futura, tendrían efectos adversos en la coalición o bloque en el poder, y iv) la expectativa racional de quie-

\footnotetext{
${ }^{7}$ Ante una falla sistémica de coordinación de la acción colectiva, una economía atrasada queda atrapada en un equilibrio ineficiente. "[En tales condiciones]... una perturbación lo suficientemente grande puede mover a una economía a un nuevo equilibrio" (Hoff y Stiglitz, 2002). Ese movimiento está mediado por la política, pero con fuertes restricciones dada la "racionalidad" de los actores centrales, o sea, de quienes detentan el poder. "Con expectativas racionales los participantes anticipan las consecuencias de cualquier acción... Ellos se resistirán a una mejora del tipo Pareto... si ello es a la larga desventajosa para sus partidarios" (ibid., p. 430).
} 
nes detentan el poder; su visión de futuro más probable los induce a oponerse a las reformas (Hoff y Stiglitz, 2004, pp. 395, 403, 429-410; North, 1984, p. 44).

\section{EL SOFTWARE COMO EJE DEL NUEVO PATRÓN INDUSTRIAL}

El software, junto con la microelectrónica, cómputo y las telecomunicaciones, constituyen los pilares del nuevo patrón industrial (NPI). Al ser proveedora de muchas industrias, pero también demandante de los bienes y servicios de otras, sus ramificaciones al resto de la estructura industrial se amplían continuamente a la par que se propaga la aplicación de las tecnologías de la información y la comunicación (TIC). Véase Dabat y Ordoñez (2009).

En la constitución del NPI, el software está convirtiéndose en el eje del sistema industrial y tecnológico actual, ya que su funcionalidad transforma radicalmente la organización de las actividades humanas. Uno de los efectos primordiales del software es cambiar el entorno. En el pasado, nuestro entorno estaba dado; estábamos rodeados de objetos pasivos y artefactos y la interacción era interpersonal, constante. Crecientemente, el software ha ido creando un entorno con objetos inanimados con el que interactuamos de maneras muy sofisticadas. Esa forma novedosa de interacción se basa en el hecho que gracias al software el ser humano se comunica con las máquinas y las máquinas se comunican entre sí. Para efectuar esa interacción se han creado sistemas crecientemente complejos que ejecutan funciones de comunicación, coordinación e información, vitales para todas actividades de las organizaciones y la sociedad (Messerschmitt y Szyperski, 2003).

\section{La tecnología del software: Qué es el software y para qué sirve}

Un programa de software consiste en un conjunto de instrucciones generadas por un programador y/o equipo de programadores para que una computadora o red de computadoras realice un conjunto detallado de acciones que permitan procesar, almacenar y comunicar un contenido informativo. Esas acciones están incorporadas en un algoritmo que describe esas acciones y la secuencia en la que deben ejecutarse.

El software está presente en todas partes. Virtualmente todos los productos que tienen un desempeño, que deben ejecutar una función, tienen un software incrustado (integrado de origen). El funcionamiento de las organizaciones 
de todo tipo, en la industria, la educación y el gobierno depende crecientemente del software.

Hay diferentes clasificaciones de los tipos de software tomando en cuenta que se trata de un bien inmaterial, equiparable a la información, pero que necesita un soporte físico. La información usa un medio material para su almacenamiento y acceso, como el papel o un disco, en tanto que el software requiere un procesador computacional para realizar su función. En la medida en que el software trabaja en concordancia con un procesador material (y con otros medios materiales como networks, routers, discos, etcetéra) asume en la práctica propiedades tanto de bien inmaterial como de bien material. Las dificultades de su registro se explican en Mochi (2006).

En el sentido anterior, y desde el punto de vista de la organización industrial, se proponen varias clasificaciones del software. El software como producto (denominado también empaquetado) es aquel en el cual no hay acceso a las funciones, si no se ha adquirido previamente un portador material, primordialmente un disco con almacenamiento magnético (el caso del Windows de Microsoft y las aplicaciones de Oracle, de SAP, etcétera). En cambio, el software como servicio consiste en la actividad de programación ejecutada en redes (locales o amplias como Internet) o directamente en las computadoras de los usuarios finales; el portador material se reduce al equipo receptor. Nos referimos como software a la medida a aquel creado específicamente para un usuario o grupo de usuarios que adoptan determinada plataforma. ${ }^{8}$ El servicio se ha universalizado debido a la creciente complejidad del software, y las organizaciones requieren mantenimiento, seguridad y actualización de sus sistemas o plataformas.

Desde el punto de vista de la funcionalidad, hay tres tipos de software que están incorporados a la computadora:

i) Sistema input-output (BIOS). Controla las funciones de bajo nivel de la computadora (acceder al sistema operativo de un disco) y es específico para el diseño de la computadora. Es software elemental incrustado.

ii) Software de infraestructura. Sirve para hacer funcionar las aplicaciones. Incluye al sistema operativo.

\footnotetext{
${ }^{8}$ Como regla se interpreta que entre mayor sea la proporción de la producción en paquete de uso universal, en comparación con el software a la medida o personalizado, más desarrollada estará la industria. Pero la creciente complejidad de los sistemas ha hecho necesario que un proveedor especializado brinde los servicios, a la medida del usuario.
} 
iii) Software de aplicación. Proporciona capacidades específicas para las necesidades de usuarios finales. Depende del software de infraestructura, que a su vez depende de las capacidades del equipo.

A los anteriores se les pueden añadir los componentes de software (elementos incorporables a las aplicaciones, adquiribles independientemente) y las herramientas (tools), que ayudan a los desarrolladores automatizando tareas.

La anterior clasificación define el producto o servicio vendible y por ende la estructura de la industria. Ello con la salvedad de que al estar representado digitalmente y poder reproducirse sin costo y siendo un bien no rival, requiere una estructura específica para transferirlo al usuario final, consistente en privilegiar la cesión mediante una licencia, con cláusulas de derechos de propiedad para impedir el acceso a quien no esté autorizado.

\section{La estructuración sectorial del software}

La clave de la estructura industrial de la industria del software radica en su cadena de valor, que incluye primero a los productores (suppliers), cuyos principales agentes son:

i) Productor de software de aplicación. Es el desarrollador que atiende las necesidades de las organizaciones usuarias finales.

ii) Productores de software de infraestructura. Atiende la descomposición del sistema de software en módulos, su funcionalidad e interacción.

iii) Integrador de sistema. Consiste en adquirir software de aplicación e infraestructura de varios productores y hacerlos funcionar conjuntamente.

Otra categoría es la de proveedores (providers) de servicios, que se especializan en la operatividad. La operatividad requiere calificación especial para mantener el funcionamiento del sistema, desde el punto de vista de la seguridad, la configuración, etcétera. Mientras los productores atienden a los usuarios como clase o grupo, los proveedores atienden las necesidades cotidianas de los usuarios específicos. Las categorías son las mismas: $i$ ) proveedores de servicios de aplicación; ii) proveedores de servicios de infraestructura, y iii) integradores de sistema.

La organización industrial no ha permanecido estática. En la era mainframes (o sea de las computadoras de gran tamaño), las operaciones se ejecutaban en 
una gran computadora propiedad de una organización usuaria, que la operaba directamente y que podía haberla desarrollado su departamento interno de sistemas.

En la actualidad, las aplicaciones son adquiridas crecientemente de compañías especializadas que las desarrollan para el mercado. Una de las primeras aplicaciones fue la data base management system (DBMS), que sirve para la adquisición, gestión y recuperación de datos de negocios. En la era desktop (de las computadoras de escritorio) aparecieron las aplicaciones para elevar la productividad individual. En esta etapa, la carga de aprovisionamiento y operación recaía en el usuario final, lo que resultaba en un caos en los sistemas de gestión de los recursos informativos.

La era de las computadoras en redes trajo oportunidades y cambios importantes. Las computadoras se conectaron a partir de una relación cliente-servidor. El efecto inmediato fue centralizar la responsabilidad de las operaciones. También aparecieron los proveedores de servicios en red. Como tenía poco sentido que una organización abasteciera y operara su propia red, muchas organizaciones subcontrataron los servicios en red, incluso de su red local de esos nuevos proveedores especializados. Como se advierte, Internet ha transformado irrevocablemente la tecnología del software y la organización de la industria, dando lugar a una enorme ampliación en la variedad de productos y una nueva modalidad de distribución, con costos considerablemente más bajos.

\section{El software y sus servicios como industria de derrama económica}

Desde el punto de vista del desarrollo económico, el software tiene una repercusión centralizadora equivalente a la industria textil o de máquinas herramientas en la industrialización del siglo XIX. En esas industrias, la capacidad de producción y la capacidad tecnológica estaban ligadas, debilitándose esa relación en el siglo XX debido a la especialización y a la separación entre proveedores y usuarios de maquinaria y equipo (Bell y Pavitt, 1992). La industria del software ha tendido a restablecer ese vínculo debido al peso que tiene el conocimiento en las etapas clave de su desarrollo.

Debido a su función centralizadora en las TIC, el desarrollo de una industria competitiva de software equivale a crear una economía basada en el conocimiento. En las economías más desarrolladas del mundo, como Estados Unidos, Japón y Alemania, el sector de software ocupa un lugar central por la consideración anterior; al mismo tiempo, las economías de reciente industrialización que crecen más rápidamente, como China, la India y, en menor medida, Brasil, están 
desarrollando esa industria a pasos acelerados, en conexión con la asimilación del nuevo paradigma, la modernización de su infraestructura y una mayor educación y capacitación de la población. Sin embargo, la edificación nacional de una industria de servicios de software no sigue un mismo patrón, en parte por la amplitud del sector y la conjugación con las trayectorias de desarrollo nacional y local. Ello se pondrá de manifiesto al efectuar más adelante una breve revisión de las experiencias de India, Irlanda, China y Brasil.

México se encuentra en el umbral de una transición, pero muy lejos de las economías dinámicas que se mencionan. Su inserción en la economía global del conocimiento cobró dinamismo en la década de los noventa, aunque principalmente en calidad de proveedor subordinado en las cadenas globales de hardware (computadoras, equipo de telecomunicaciones, audio y video y semiconductores). Por el hecho mismo de haberse iniciado la integración a la economía del norte de América, creó una oportunidad para impulsar a este sector clave y realimentar el desarrollo de los sectores ligados al hardware que funciona con el llamado software embebido.

\section{EL DESARROLLO DE LA INDUSTRIA DE SERVICIOS DE SOFTWARE EN MÉXICO EN UN MARCO INTERNACIONAL COMPARATIVO}

\section{Requerimientos básicos y modalidades nacionales}

El desarrollo de la industria del software dependió históricamente del hardware computacional. Hasta que la población de computadoras no se multiplicó y adquirió una configuración accesible al usuario, el software fue un integrante más del sistema computacional, sin identidad como producto específico. Los grandes usuarios tenían su departamento interno de desarrollo de software.

El paso definitivo hacia una industria específica, primero en Estados Unidos, fue la decisión de IBM en 1968 de "desatar" el hardware del software en su sistema 360. De allí derivó la decisión de comprar el sistema operativo (MSDOS) de Microsoft. En la década de los noventa concurrió mundialmente una amplia gama de grandes productores de software, especialmente en el sector de las aplicaciones. Ante el creciente déficit de especialistas en programación (ingenieros en ciencias computacionales y en software) en los países desarrollados, se recurrió crecientemente a la inmigración, al outsourcing, cuya modalidad interempresa implica outshoring (extraterritorialidad). Por la forma en que se ha dado el desarrollo de la industria en países tardíos A, parecen existir modalidades 
nacionales de desarrollo de la industria e inserción en la demanda mundial. Siguiendo el estudio compilado por Arora y Gambardella (2005), se advierte que India, Irlanda, Israel y la China siguen modalidades que presentan algunas diferencias (véase también Saxenian y Hsu, 2001). Brasil empieza a desarrollar una impresionante industria que abastece al mercado interno, pero con baja interacción mundial (Bottelho, A., et al., 2005). Diversos países en los cuales el trabajo calificado de científicos e ingenieros se paga con salarios comparativamente más bajos, tienen potencial para desarrollar la industria debido a la interacción internacional favorable, pero requieren complejas políticas de impulso y coordinación, centralizadas o descentralizadas, que remiten a la superación de lo que denominamos previamente, siguiendo a North et al. (2009), Estado natural.

En las cuatro modalidades citadas, el apoyo estatal ha sido decisivo, aunque difiere de país a país. En tres de ellas fue decisiva la diáspora como medio de vinculación con el centro tecnológico mundial (costa oeste de los Estados Unidos). La experiencia de la India muestra que es posible convertirse en proveedor mundial de servicios de software, empezando en el segmento bajo la cadena de valor y sin tener, al comienzo, un mercado interno para productos o servicios o incluso una limitada difusión de las TIC (Athreye, 2005). La condición es que se cuente con otras ventajas competitivas: abundancia de ingenieros y técnicos a bajas tasas salariales relativas, dominio del idioma inglés, un Estado orientado activamente a fomentar la industria. ${ }^{9}$ La experiencia de Irlanda indica que se puede avanzar de la mano de las empresas transnacionales, aprovechar nichos en el mercado internacional para que se desarrollen las empresas nacionales, reiterando la importancia de la abundancia de cuadros altamente calificados, así como de la intervención activa del Estado (Sands, 2005). El caso de Israel corrobora la importancia del factor humano, del idioma inglés y de la intervención pública y de contar con la diáspora más desarrollada que posibilitó el salto a un segmento alto de la cadena de valor (Breznitz, 2005).

En lo referente a China y Brasil, ambos corroboran la función que puede cumplir un gran mercado interno potencial, en comparación con las exportaciones (Tschang y Xue, 2005; Bottelho, A., et al., 2005). Pero en Brasil el mercado interno se ha expandido como una respuesta a los cambios en la relación con el

\footnotetext{
${ }^{9}$ En las cuatro modalidades citadas, el apoyo del Estado ha sido decisivo, pero con diferencias de país a país. La tendencia histórica es que, excepto en China, las reformas neoliberales han modificado el carácter de la acción pública, centrándola en una función de coordinador horizontal (sin discriminación entre agentes). Ese cambio se dio cuando las bases de las industrias en India, Irlanda e Israel estaban constituidas, pero afectó limitadamente a Brasil y más a México, como veremos.
} 
mercado global (la liberalización comercial abatió el costo del hardware y atrajo a empresas extranjeras).

\section{El desarrollo y la modalidad territorial de la industria en México}

Desde fines de los años ochenta el gobierno mexicano (mutando políticamente del corporativismo autoritario al neoliberalismo) había renunciado formalmente a las políticas sectoriales asumiendo más bien los preceptos de horizontalidad prescriptos por la ortodoxia (Clavijo y Valdivieso, 1994). La administración de Vicente Fox, con una orientación empresarial, cambió de enfoque y a partir de 2000 comenzó a formular programas sectoriales, bajo la conducción de la Secretaría de Economía y dentro del marco de la Ley de Ciencia y Tecnología de 2002 (véase Foro Científico y Consultivo, 2006). En el caso del software, debido principalmente a la influencia de varios científicos e ingenieros, entre los que destaca Hanna Oktaba, investigadora del Instituto de Investigaciones en Matemáticas Aplicadas y Sistemas (IIMAS) y del Departamento de Matemáticas de la Facultad de Ciencias de la UNAM, se formuló el Programa para el Desarrollo de la Industria del Software (Prosoft) que propuso una estrategia y metas explícitas para 2013, entre las que destacaba alcanzar una producción de software de 5 mil millones de dólares (véase Secretaría de Economía s/f).

El inicio de esa década fue crítico para México porque representó la culminación del auge exportador en electrónicos (en 1990, se exportaron a Estados Unidos unos 6500 millones de dólares, para alcanzar un máximo de 35500 en 2000),,$^{10}$ lo que dejó una secuela de aprendizaje relativamente pobre, aunque las oportunidades empresariales fueron sustanciales; la imposibilidad de mantener el ritmo anterior de las exportaciones ${ }^{11}$ estaba relacionada con factores cíclicos (la crisis de las telecomunicaciones e Internet, de 2001), pero también con el nuevo papel de China como potencia electrónica mundial (Ernst, 2010; Dabat et al., 2005).

Esta evaluación de la industria del software en la década pretende determinar los avances en un marco internacional comparativo, en el sentido de vías de desarrollo (Dabat, 1994). Existen numerosas limitaciones para compilar datos confiables para ahondar las comparaciones sobre esta nueva industria por sus

\footnotetext{
${ }^{10}$ Datos de la CEPAL y de la Secretaría de Economía.

${ }^{11}$ Protagonizada por empresas denominadas maquiladoras de exportación y complejos OEMContract Manifacturers, con limitada participación de empresas locales.
} 
atributos de bien inmaterial que se distribuye crecientemente por redes, por lo que se ha recurrido a fuentes especializadas, como Digital Planet de WITSA, trabajo de campo y un conjunto de publicaciones previas. ${ }^{12}$

En el trabajo de campo en las cuatro ciudades se pretende conocer la configuración general de la industria, el tipo de empresa doméstico-local que ha surgido en las cuatro ciudades, su capacidad de aprendizaje y la conexión con agentes globales.

\section{Algunos elementos de ubicación nacional}

La liberalización comercial iniciada unos años antes que la de Brasil, abatió, desde fines de la década de los ochenta, el costo de los equipos de cómputo y sentó las bases para el desarrollo del sector de las TIC y del software en particular. En México, el tamaño del mercado de las TIC pasó de 18 mil millones en 2001 a 33 mil millones en 2008, poco menos de la mitad del de Brasil y de la India. La parte predominante de los gastos en TIC corresponde a telecomunicaciones (63\%), seguidas de hardware computacional (21\%) y software (3\%). En los nuevos tigres, este último indicador oscila entre 4 y $5 \%$ (véase cuadro 1 ).

El tamaño de mercado coloca a México en una posición muy distante no sólo de las naciones líderes, como Estados Unidos (150 mil millones), Japón (22 mil millones) y Alemania (30 mil millones), sino de las naciones emergentes de alto crecimiento en el sector: Brasil: (4 mil millones) e India (5 mil millones). Un mercado de software que represente $1-1.5 \%$ del PIB se considera de alto desarrollo (naciones líderes) y de entre 0.4 y 0.5 de dinamismo emergente (India, Brasil, Taiwán, Singapur, Finlandia). México se ubica en 0.1, debajo de Argentina, con $0.5 \%$ (WITSA, op. cit.).

Como parte del desarrollo del ecosistema, la importación masiva de software empaquetado predomina en las primeras etapas, de modo que para el 2000 el 90\% de la demanda se satisfacía por medio de importaciones (Mochi, 2006). (véase cuadro 2). La empresa nacional, en escala artesanal, comenzó en el escaño más bajo produciendo servicios a la medida para pequeños usuarios. En los escaños bajos del desarrollo del ecosistema los grandes usuarios (empresas y gobier-

\footnotetext{
${ }^{12}$ En las cuentas nacionales de México, la producción de software se registra en el grupo 6821 , que se sesga hacia el producto empaquetado, dejando virtualmente fuera los servicios (véase Mochi, 2006). Ante la ausencia de una entidad centralizadora que estime la producción como producto y como servicio, se recurrió, como hace Mochi, a los datos de gasto tal como los compila principalmente WITSA (2006-2008; véase cuadro 1).
} 
Cuadro 1. El mercado mundial de tecnologías de la información y la comunicación 2001-2006

(Millones de dólares)

\begin{tabular}{|c|c|c|c|c|c|c|c|c|c|c|}
\hline País & 2001 & 2002 & 2003 & 2004 & 2005 & 2006 & 2007 & 2008 & TCMA & $\begin{array}{c}\text { TC } \\
2001- \\
2008\end{array}$ \\
\hline $\begin{array}{l}\text { Estados } \\
\text { Unidos }\end{array}$ & 876560.70 & 892124.70 & 933970.10 & 1015554.50 & 1093625.10 & 1151554.00 & 1187417.35 & 1235522.18 & 4.5 & 176.96 \\
\hline Canadá & 42773.50 & 44896.20 & 50767.20 & 58241.70 & 65699.40 & 71867.40 & 74406.12 & 76052.80 & 8.5 & 472.52 \\
\hline México & 18246.60 & 19489.30 & 19891.40 & 22682.50 & 25363.70 & 27770.60 & 30290.18 & 33257.00 & 6.9 & 334.63 \\
\hline $\begin{array}{l}\text { América } \\
\text { Latina }\end{array}$ & 65756.40 & 63587.10 & 74880.60 & 88700.80 & 110413.20 & 121960.40 & 126573.10 & 132539.17 & 10.0 & 640.43 \\
\hline Brasil & 30584.60 & 31675.00 & 41217.10 & 48330.00 & 62064.50 & 68670.30 & 69733.29 & 71405.38 & 12.8 & 1066.21 \\
\hline $\begin{array}{l}\text { Argen- } \\
\text { tina }\end{array}$ & 10772.80 & 6508.50 & 8261.70 & 10461.60 & 13053.60 & 14841.80 & 16236.77 & 18.29118 & 5.3 & 222.30 \\
\hline Chile & 4131.30 & 4480.80 & 4878.60 & 5951.10 & 7013.50 & 7642.20 & 7965.64 & 8388.03 & 9.9 & 635.51 \\
\hline Uruguay & 1067.70 & 879.8 & 855.2 & 1018.50 & 1332.00 & 1505.70 & 1595.40 & 1729.30 & 5.7 & 246.43 \\
\hline $\begin{array}{l}\text { Europa } \\
\text { Occid. }\end{array}$ & 523364.90 & 564451.00 & 681894.70 & 781934.90 & 814360.20 & 857806.00 & 978788.88 & 1088396.31 & 8.1 & 435.27 \\
\hline Alemania & 112311.40 & 119822.80 & 146274.10 & 164235.40 & 169830.30 & 179120.30 & 203262.34 & 223420.11 & 7.6 & 396.35 \\
\hline $\begin{array}{l}\text { Reino } \\
\text { Unido }\end{array}$ & 111229.60 & 118168.10 & 135594.00 & 157260.70 & 161580.60 & 164731.30 & 183556.47 & 202408.29 & 6.5 & 301.37 \\
\hline Francia & 84397.90 & 91225.30 & 112552.00 & 129734.90 & 134742.30 & 142338.70 & 162793.91 & 180420.74 & 8.5 & 478.34 \\
\hline España & 23729.10 & 26691.20 & 33383.40 & 38856.70 & 41614.20 & 44284.00 & 50835.66 & 57040.07 & 10.1 & 652.03 \\
\hline $\begin{array}{l}\text { Asia } \\
\text { Pacífico }\end{array}$ & 517001.90 & 520043.40 & 583639.50 & 671417.60 & 716893.60 & 771214.70 & 871848.02 & 974678.44 & 6.6 & 309.96 \\
\hline Japón & 325277.60 & 298071.20 & 322149.80 & 351707.10 & 342174.20 & 343392.50 & 374401.92 & 408211.58 & 0.9 & 25.50 \\
\hline China & 51814.60 & 62375.70 & 75400.10 & 97657.60 & 117631.50 & 142313.30 & 172380.06 & 211599.18 & 15.5 & 1691.49 \\
\hline Corea & 30894.00 & 35852.20 & 40547.20 & 46751.30 & 54442.90 & 58768.60 & 62228.18 & 66407.65 & 10.4 & 688.76 \\
\hline India & 16844.40 & 19997.30 & 25692.00 & 36164.20 & 46437.70 & 55304.30 & 65579.47 & 78644.28 & 17.8 & 2431.73 \\
\hline $\begin{array}{l}\text { Medio } \\
\text { Oriente }\end{array}$ & 19533.60 & 21007.40 & 22454.60 & 25986.20 & 30056.40 & 32568.80 & 35229.47 & 38179.71 & 8.3 & 460.78 \\
\hline Israel & 8259.30 & 8050.20 & 8618.90 & 9333.10 & 10213.00 & 11065.90 & 11658.90 & 12334.24 & 4.8 & 195.10 \\
\hline
\end{tabular}

no) siguen el modelo in-house (Hualde y Mochi, 2008). Mochi (2006) estimaba que para 2002 el total de facturación del software in-house fue de unos 750 millones de dólares, casi igual al tamaño del mercado de software empaquetado en ese mismo año. ${ }^{13}$ Carecemos de datos más recientes, pero de acuerdo con la información obtenida por entrevistas, el gobierno de Calderón cambió de estrategia. Las grandes entidades federales (comenzando por el Instituto Federal Electoral, el

${ }^{13}$ La duda que queda de la citada información es que los departamentos de informática de las grandes empresas sólo limitadamente son desarrolladores de software y privilegian la compra de software empaquetado, de modo que parece que hay cierta duplicación en los datos. Ese punto requiere mayor investigación directa. 
118 ECONOMÍA: TEORÍA Y PRÁCTICA • Nueva Época, número 33, julio-diciembre 2010

Cuadro 2. El mercado mundial de software computacional, 2001-2006 (Millones de dólares)

\begin{tabular}{|c|c|c|c|c|c|c|c|c|}
\hline País & 2001 & 2002 & 2003 & 2004 & 2005 & 2006 & 2007 & 2008 \\
\hline $\begin{array}{l}\text { Estados } \\
\text { Unidos }\end{array}$ & 98103.3 & 97204.4 & 104918.3 & 115568.1 & 125847.2 & 135655.1 & 140568.9 & 148392.6 \\
\hline Canadá & 4185.2 & 4297.2 & 5259.6 & 6263.2 & 7213.2 & 8007.6 & 8326.9 & 8586.6 \\
\hline México & 548.6 & 610.8 & 639.7 & 692.1 & 776.5 & 845.1 & 911.0 & 977.1 \\
\hline \multicolumn{9}{|l|}{$\begin{array}{l}\text { América } \\
\text { Latina }\end{array}$} \\
\hline Brasil & 1697.5 & 1786.8 & 2468.7 & 2876.7 & 3565.9 & 3827.9 & 3802.5 & 3785.2 \\
\hline Argentina & 371.9 & 379.7 & 430.5 & 488.9 & 571.1 & 629.9 & 684.2 & 770.5 \\
\hline Chile & 100.6 & 101.9 & 117.8 & 145.4 & 172.5 & 190.5 & 201.5 & 441.1 \\
\hline Uruguay & 36.2 & 42.7 & 34.8 & 39.1 & 51.0 & 57.9 & 61.6 & 67.3 \\
\hline \multicolumn{9}{|l|}{$\begin{array}{l}\text { Europa } \\
\text { Occid. }\end{array}$} \\
\hline Alemania & 1312.0 & 14527.4 & 18380.0 & 21317.7 & 22358.3 & 23802.3 & 27027.0 & 29973.9 \\
\hline $\begin{array}{l}\text { Reino } \\
\text { Unido }\end{array}$ & 12315.8 & 13472.0 & 16466.9 & 20225.9 & 21576.3 & 22650.3 & 25811.8 & 29125.2 \\
\hline Francia & 9202.5 & 10096.6 & 12908.5 & 15365.9 & 16432.4 & 17675.4 & 20295.0 & 22688.3 \\
\hline España & 2009.1 & 2241.8 & 2919.0 & 3459.8 & 3877.1 & 4379.3 & 5490.2 & 6712.1 \\
\hline \multicolumn{9}{|l|}{$\begin{array}{l}\text { Asia } \\
\text { Pacífico }\end{array}$} \\
\hline Japón & 13435.8 & 13100.3 & 14719.9 & 16810.4 & 17014.1 & 17812.8 & 20339.1 & 22335.4 \\
\hline China & 1657.9 & 2252.6 & 3344.4 & 5295.4 & 7939.5 & 11376.0 & 16327.7 & 23001.8 \\
\hline Corea & 918.6 & 1115.8 & 1355.9 & 1733.7 & 2261.5 & 2848.5 & 3499.2 & 4268.2 \\
\hline India & 455.9 & 588.3 & 947.5 & 1350.4 & $1,907.7$ & 2518.6 & 3335.8 & 4378.4 \\
\hline \multicolumn{9}{|l|}{\begin{tabular}{|l|l} 
Medio \\
Oriente \\
\end{tabular}} \\
\hline Israel & 527.2 & 522.3 & 569.3 & 653.0 & 700.9 & 767.6 & 829.3 & 896.1 \\
\hline
\end{tabular}

Instituto Mexicano del Seguro Social, la Secretaría de Relaciones Exteriores, entre otras), han contratado los servicios de software de compañías en su mayor parte extranjeras (de la India, Estados Unidos y España). Se requieren mayores estudios para determinar las causas de estas decisiones, pero sabemos que se basan en las disposiciones de la Ley de Ciencia y Tecnología aprobada en 2001, en la normatividad de Conacyt y en las diversas disposiciones que forman parte de la reglamentación de importación temporal para la exportación. Considerando la gran influencia que tienen las empresas propietarias de plataformas (SAP, Microsoft, Oracle, etcétera) en los medios gubernamentales y empresariales, la opción del 
gobierno para desligarse de esa dependencia estaba por tanto en: $i$ ) hacer obligatorio el uso de software libre en el nivel gubernamental, como en Brasil, en cuyo caso se podía traspasar el mercado a proveedores locales; $i$ i) recurrir a proveedores extranjeros de "genéricos", como la India y España, o de tamaño medio como Perot Systems, que ofrece paquetes de servicio integral o menor costo, o bien iii) buscar proveedores nacionales que tuvieran economías de escala y capacidad de ejecutar grandes proyectos. ${ }^{14}$

En lo concerniente a iii), si a fines de los años noventa la industria nacional estaba fragmentada territorialmente y predominaron las pequeñas empresas con capacidades limitadas para alcanzar economías de escala, ${ }^{15}$ ampliar la gama de productos y ofrecer soluciones avanzadas, a fines de la siguiente década la situación cambió sustancialmente, por lo menos en las dos principales aglomeraciones (el Distrito Federal y Guadalajara), y en mucho menor medida Tijuana, aunque en la actualidad persisten debilidades, lo que hace dudoso que sean los beneficiarios del cambio de estrategia del gobierno de Calderón. A principios de 2000, en el ámbito nacional de acuerdo con Mochi (2006), había unas 390 empresas registradas, de las cuales la mitad tenía menos de 15 empleados. Nuestra investigación de campo en la ciudad de México, basada en el Directorio de AMITI, que agrupa a 64 socios, la planta laboral promedio es de 40 empleados, ofreciendo servicios básicos y avanzados de software (servicios en red, integradores de sistema, aplicaciones a la medida, servicios especializados, e incluso software incrustado, el renglón más avanzado, véase anexo). Identificamos tanto en el Distrito Federal como en Guadalajara y en menor medida en Tijuana, lo que denominamos empresas "científicas". Las definimos en función de los siguientes indicadores: $i$ ) vinculación con universidades o tecnológicos; $i i)$ alta proporción de especialistas en ingeniería en la planta laboral; iii) certificación nacional e internacional; iv) infraestructura (plataformas y lenguajes) avanzada, y v) asentamiento en nichos de mayor valor agregado.

En las dos principales aglomeraciones, el Distrito Federal y Guadalajara, la calidad de la formación de ingenieros y técnicos ha aumentado, aunque es desigual. En Guadalajara, las entrevistas dejaron en claro, además de su percepción

\footnotetext{
${ }^{14}$ La capacidad de ejecución de grandes proyectos deja fuera a la gran mayoría de las empresas entrevistadas, que están en el rango de 50-100 empleados. Las empresas Hildebrando y Sofftek tienen capacidad para ejecutar grandes proyectos. La primera recibió el conocido contrato para el Instituto Federal Electoral, proyecto menor en comparación con el contrato que recibió una empresa española para digitalizar información de los pasaportes.

${ }^{15}$ Principio que se aplica en las que operan como "fábricas de software".
} 
del bajo nivel de los egresados, que no hay los suficientes egresados de las carreras de ingeniería y ciencias como para sostener la expansión de las empresas científicas. En la UNAM, por ejemplo, el cupo de admisión para carreras de ingeniería relacionadas con la electrónica e informática es de alrededor de una décima parte de la admisión de abogados o de contadores.

Las exportaciones son el indicador primordial de la competitividad de una industria y las cantidades empezaron a despuntar entre 2005-2009. Mochi (2006) estima 400 millones en la categoría de empaquetado para 2006, combinando exportaciones de filiales de empresas extranjeras, los gigantes nacionales (como Hildebrando y Sofftek) y un grupo cada vez mayor de las empresas científicas. Pero ante el desafío de los proveedores globales de "genéricos", se requiere desarrollar más las capacidades competitivas de los start-up locales o nacionales, lo cual a su vez requiere lo que denominaremos plataformas institucionales. Para concretar una plataforma institucional se necesita una representación política en las esferas de toma de decisiones.

\section{Las modalidades del desarrollo de los proveedores de servicios de software y los nodos territoriales en las cuatro ciudades}

El desarrollo de la industria en México adquirió una modalidad territorial, pero con algunas diferencias de trayectoria. Una de esas modalidades está centrada en el Distrito Federal y en Guadalajara, con diferencias de densidad del ecosistema. En el Distrito Federal, como ciudad macro, la enorme concentración de universidades, usuarios, públicos y privados, ha creado un mercado relativamente grande, con cuatro tipos de oferentes: los propietarios de plataformas, los proveedores de globales de genéricos y las empresas científicas locales (de tamaño medio) y un puñado de lo que podemos llamar eufemísticamente campeones nacionales (Hildebrando, Soffteck, las Fábricas de Software de Telmex). El mejor ejemplo de una empresa científica es Ultrasist, que fue la primera en obtener en México la certificación CMMI-5. En entrevista, ${ }^{16}$ la matemática Guadalupe Quijano, directora general, la describió como una fábrica de software, con procesos estandarizados para proporcionar soluciones eficaces a sus clientes, principalmente grandes instituciones financieras. El dilema de la empresa no está en el reclutamiento de ingenieros y matemáticos competentes, porque su relación con la Facultad de Ciencias de la UNAM y la asesoría que les brinda Hanna Oktaba desde

\footnotetext{
${ }^{16}$ Efectuada el 4 de noviembre de 2009.
} 
2009, facilitaba la solución de ese problema, sino que no veía mucho sentido en crecer si el gobierno daba preferencia a las empresas extranjeras, citando un contrato de Tata Consulting. ${ }^{17}$

Otra empresa exitosa es Neology, que se especializa en software embebido, orientado al mercado internacional. ${ }^{18}$ Hay otras empresas doméstico-locales especializadas en software incrustado, sobre todo automotriz, encabezadas por ingenieros principalmente de la Universidad de Querétaro. ${ }^{19}$ Se requiere, no obstante, mayor investigación para establecer la función de las empresas doméstico-locales cuyo modelo es ASCI. ${ }^{20}$

Otra empresa de perfil científico es CERTUM, cuyo presidente informó en la entrevista que mantiene contactos informales con investigadores de la Universidad Autónoma de Puebla para apoyar la certificación de proyectos de robótica. La empresa mantiene también contactos con el Instituto de Tecnológico de Monterrey (ITESM), pero califica desfavorablemente en el nivel operativo por la alta rotación de personal. De la UNAM considera que el principal problema es su excesivo aparato administrativo y su baja apertura ante los organismos privados. ${ }^{21}$

La lógica territorial en Guadalajara presenta algunas diferencias. La alta concentración de empresas OEM-OBM tuvo dos efectos: $i$ ) fue una escuela para desarrollar el talento local en ingeniería y gerencia, que lideró el desarrollo de una nueva generación de empresas locales (el canon de esa primera generación está representada por ASCI y MIXBAL), y ii) indujo, como respuesta local, la demanda de servicios avanzados, entre ellos software incrustado. A su vez, la interac-

\footnotetext{
${ }^{17}$ El contrato no médico más importante entre el IMSS y la empresa india Tata Consulting Services de México (filial) otorgado a una sola empresa, arrojaba la irregularidad de que incluirían la facturación en un solo mes -diciembre de 2008- de $420 \mathrm{mil} \mathrm{horas/hombre} \mathrm{de} \mathrm{consultoría.} \mathrm{Eso}$ equivaldría a destinar 2625 programadores de tiempo completo, en turnos de ocho horas durante cinco días laborables, sólo para dar servicio a ese contrato del Instituto Mexicano del Seguro Social. De acuerdo con su ficha técnica, Tata Consulting Services opera en México con una planta laboral de entre 500 y 1000 empleados (Reporte Índigo).

${ }^{18}$ De acuerdo con declaraciones de su presidente, Francisco Martínez, la empresa tenía en 2008 capacidad de producción de 4 millones de etiquetas para control vehicular, destinadas a México y Estados Unidos (Reforma, 17 de noviembre de 2009).

${ }^{19}$ Entrevista con el ingeniero Juan Carlos Becerril, de Fumex, 23 de septiembre de 2009.

${ }^{20}$ Agradecemos a la ingeniera Margarita Solís el proporcionarnos copia de su estudio pionero sobre el software embebido (o incrustado) y el contacto con la oficina en el Distrito Federal de Fumex, que ha promovido el estudio del software incrustado en México.

${ }^{21}$ Entrevista efectuada el 9 de octubre de 2009. A la pregunta de cómo evaluaba el Fondo Prosoft, declaró que para sus intereses era inoperante porque la empresa debe aportar $75 \%$ de la inversión.
} 
ción territorial aceleró la difusión de las herramientas de software, la relación universidad-industria, la incubación de empresas (Cinvestav-Guadalajara, CTS). El apoyo del Prosoft ha sido decisivo, siendo Jalisco la entidad con mayores asignaciones (Montiel, 2009). La formación de un núcleo promotor encabezado por la actual dirigencia de la Cadena de la Industria Electrónica (Cadalec) y Canieti-Occidente (Cámara Nacional de Tecnologías de la Información) definió la estrategia para 2005-2010. La conmoción provocada por la crisis de 2001, causante de una importante migración de OEM, y de CM, cambió en parte el perfil de especialización local, e incentivó la apertura de las empresas, la mayoría de las cuales entrarían en la categoría que llamamos científicas. En las entrevistas efectuadas entre el 21 y el 23 de septiembre de 2009 se identificaron algunas características de la modalidad territorial, que también forman parte del modelo multifactorial.

En 2000 se creó el Consejo Estatal de Ciencia y Tecnología, y dos años después el Instituto Jalisciense de Tecnología de la Información (Ijalti), que promovieron, con el apoyo de la Canieti-Occidente y Cadalec, dos estrategias para la década de 2000, que no están conciliadas y han provocado controversia. Respecto a la primera vertiente estratégica, Ijalti promovió, con apoyo estatal y del Prosoft, la concentración física de pequeñas y medianas empresas para formar centros de Software. ${ }^{22}$ El primero de ellos se instaló en un viejo pero amplio edificio, muy cerca del centro de la ciudad (otro proyecto está en ejecución, llamado Parque del Software, en Zapopan el Grande). En el Centro de Software de Guadalajara seleccionamos 10 pequeñas empresas, entrevistando a gerentes e ingenieros. El cuadro general que se obtuvo es el siguiente: el nivel de competencia empresarial es alto (probablemente INNEVO que obtuvo el CCMM 1 este año sea la empresa más avanzada); las empresas del Centro de Software se especializan en software a la medida, aplicativo y multimedia y de servicios específicos (seguridad, calidad, verificación, actualización) con herramientas avanzadas y, en los cuadros de nivel alto hay una proporción elevada de ingenieros con maestría, doctorado y dominio del inglés. La queja más común es la deficiente formación de los egresados en ingeniería, que forman el estrato de base. Un gerente explicó que para cubrir una plaza de programador, seleccionan a uno de cada 50 aspirantes. ${ }^{23}$

\footnotetext{
${ }^{22}$ Los directivos del Ijalti estiman que existen en la localidad 350 desarrolladores de software, pero no diferencian entre empresas locales y extranjeras.

${ }^{23}$ El dueño y gerente de Estrasol expresó un punto de vista similar, subrayando la incongruencia entre la currícula de las universidades y los requerimientos de la industria, aunque reconocen avances recientes.
} 
Otro expresó que la universidad menos acoplada a las necesidades de la industria es la Universidad de Guadalajara.

Visto en conjunto, el talón de Aquiles de la industria en Guadalajara es la fragmentación. En entrevista Araceli Lozada, directora de la empresa integradora Aportia, explicó que el interés por formar parte de esa asociación ha decaído, pese a los beneficios que ofrece en cuanto capacitación, mejoras de organización, tramitación de propiedad intelectual, etcétera. La otra vertiente estratégica apoyada vigorosamente por la Cadalec, según explicó Lilia Borrego de CadalecOccidente, es el outsourcing, en cual el territorio local de Guadalajara no actúa como generador empresarial sino como receptor territorial de empresas foráneas. El gobierno del estado adoptó el modelo ITO/BPO, comúnmente denominado "aplicaciones de Internet" y se propuso atraer a empresas extranjeras para aprovechar el pull de mano de obra barata para tres actividades básicas (administración de pagos, supply/demand y call centers).

En 2005 comenzó operaciones Hispanic Teleservices Corporation, un año después Teletech Holding y Perot System Corporation, seguidas de Tata Consulting. Los promotores argumentan que los beneficios para el estado son los siguientes:

i) El ITO/BPO, incluyendo call centers, crea empleos con relativamente poco capital.

ii) La implantación de operaciones es rápida y por ello la incorporación de personal es inmediata.

iii) Los requerimientos técnicos son bajos, en especial en los call center o en las actividades de programación.

El concepto de competitividad es singular, de acuerdo con el planteamiento de Canieti-Cadalec: "si en las principales ciudades de la India la demanda de personal excede a la oferta, sus empresas abrirán operaciones en México, lo que representa una oportunidad" (Canieti, mayo-octubre de 2007). Los pequeños empresarios están sumamente molestos porque Tata Consulting contrató de inmediato a 600 programadores de software, ofreciéndoles una modesta mejora de salarios, pero a cambio de un trabajo muy intensivo. ${ }^{24}$

Este giro de estrategia, más patente en Guadalajara pero presente también en el Distrito Federal, es en realidad, como se apuntó previamente, una deri-

\footnotetext{
${ }^{24}$ Declaración del director de Estrasol.
} 
vación de la filosofía de los programas de importación temporal para la exportación, que sentó las bases del auge posterior del TLCAN. La idea principal consiste en promover la actividad empresarial con el fin de atraer inversión extranjera, crear empleo e impulsar las exportaciones. En la práctica, los beneficios sociolaborales son patentes pero limitados, con efectos de disolución del núcleo endógeno, sobre todo crowding-out local. No obstante, las fuerzas locales desencadenadas son dignas de consideración y hay resultados importantes, como la multiplicación de "empresas científicas", pero contradictoriamente la estrategia estatal incentiva (con Prosoft) e inhibe a la vez (con el acceso preferencial a empresas extranjeras). Pero el problema no es estrictamente estratégico, o sea, de elección de opciones de política pública, sino institucional-estructural, ya que los grandes intereses económicos que prevalecen debilitan la integridad del núcleo ${ }^{25}$ (que depende del apoyo al aprendizaje social a partir de la promoción de la empresa nacional, la capacitación laboral, de la educación, etcétera).

Tijuana representa un caso intermedio, ya que su trayectoria histórica como gran aglomeración de maquiladoras de exportación incentivó el desarrollo del sistema educativo, de capacitación laboral y en cierta medida la infraestructura, pero con un desarrollo empresarial local considerablemente limitado, sobre todo en comparación con Guadalajara. A la par que el territorio Tijuana se convertía en asentamiento de operaciones extranjeras para equipo de audio y video, proliferaron en los años noventa microempresas de servicios de software que satisfacen la demanda local, proveniente de pequeños negocios. Las empresas entrevistadas provienen del directorio de ITBaja. Se comprobó que prevalecen las microempresas especializadas en software a la medida de tipo básico, que emplean el equipo elemental y padecen alta rotación de pasantes de ingeniería y ciencias con salarios bajos; ${ }^{26}$ empero han surgido empresas de perfil científico, de las que se identificaron dos en las primeras entrevistas (sólo se entrevistó a una de ellas). La empresa entrevistada estaba negociando en 2007 un acuerdo

\footnotetext{
${ }^{25}$ Los intereses "endógenos" están representados en la comunidad científica, tecnológica y educativa no burocratizada: los pocos cuadros de funcionarios con mentalidad "desarrollista", los pequeñas empresas de sectores como los servicios de software, biotecnología, etcétera Su capacidad de "representación" (incidencia en la implantación de políticas) es débil en tanto no estén aliados a intereses industriales poderosos. El drama mexicano, por así decir, es que, a diferencia de la India, los magnates industriales se han centrado en sectores de bajo contenido en insumos de conocimiento, con subsidio estatal asignado de forma discriminatoria.

${ }^{26}$ Hualde y Gomís (2009) comprobaron que sólo 1.5\% de las empresas locales emplea el sistema operativo Linux, $3 \%$ bases de datos con licencia libre y $5 \%$ lenguaje Java.
} 
con compañías aseguradoras del suroeste de los Estados Unidos que proporcionan servicios a los mexicanos que emigraron.

Mexicali se sitúa en el límite inferior del desarrollo del ecosistema, aunque su potencial es notorio. Tiene un rango poblacional medio, por lo que ha atraído empresas para actividades de maquila tradicional, esto es, ensamble y subensamble, avanzando a complejos automatizados. En entrevista, Arturo Lara, presidente de la Asociación de Maquiladoras de Mexicali, declaró que, excepto los productos de bajo valor agregado (cartones, cables, papel, plásticos, etcétera), no hay proveeduría local a las maquiladoras de exportación.

\section{ANÁLISIS MULTIFACTORIAL DE LA MUESTRA DE EMPRESAS DE SERVICIOS DE SOFTWARE}

\section{Tratamiento de la información}

Como se explicó en la introducción, se trabajó con tres directorios de empresas de tecnología de la información (el de AMITI, Ijalti e ITBaja, véase anexo); se enviaron cuestionarios a todas ellas (véase en anexo el cuestionario). El número de cuestionarios respondidos corresponde al menos a 30\% del total, siendo de gran representatividad para los resultados (véase anexo para el número de respuestas por localidad). La información no sólo se solicitó por medio de llamadas telefónicas y visitas, sino mediante la realización de 15 entrevistas personales (10 en Guadalajara y 5 en el Distrito Federal). En todos los casos se dio seguimiento a cada uno de los cuestionarios respondidos, atendiendo a todas aquellas dudas para la congruencia en las respuestas, repitiendo las preguntas a los voceros o representantes de las empresas. Estos criterios de revisión y verificación se mantuvieron en las cuatro aglomeraciones, en las que se obtuvo un total de 69 cuestionarios respondidos.

Las respuestas se integraron en dos bloques de variables. El primero tuvo el propósito de identificar la evolución cuantitativa del sector encuestado a partir de características generales, como año de su fundación y el número de personal de las empresas consultadas (indicador del tamaño). En el segundo bloque, del que depende la prueba de la hipótesis, se integró una serie de variables que definen el perfil "científico" de la empresa: $i$ ) nivel de calificación del personal (consolidado y en consolidación); ${ }^{27} i$ ) vinculación hacia los centros de forma-

${ }^{27}$ Consolidado: es el personal con formación superior a licenciatura; no consolidado: es el recién egresado de la educación superior y de reciente incorporación a la empresa. 
ción superior; iii) calidad de la infraestructura (plataformas y lenguajes), clasificada en avanzada e intermedia; $i v$ ) los nichos de valor agregado (alto, medio y bajo); ${ }^{28} v$ ) vinculación con los clientes (venta directa o indirecta); $v i$ ) la dispersión geográfica de los clientes (en la localidad y fuera de la localidad), y vii) el acceso a fondos sectoriales. Hacemos la descripción de ambos bloques, sus variables respectivas y las codificaciones (continuas y nominales) que se asignaron a cada una de ellas, que se describen en el cuadro 1 del anexo estadístico.

\section{Método de análisis}

Para el análisis se utilizó el método multivariado o multifactorial, diferente del análisis de componentes principales (ACP), que es el método de correspondencias múltiples (ACM). La razón para utilizar el método multivariado es su cualidad geométrica y descriptiva que permite ubicar a los individuos y las variables en una cartografía espacial (Nora Moscoloni, 2005). La segunda cualidad de este método es que permite integrar variables continuas con variables nominales, lo que debido al número de casos manejados resultó de particular utilidad, integrando las respuestas de una manera más sintética, considerando el tamaño de la muestra. Los resultados del análisis factorial se complementaron con la construcción de clases de las diferentes empresas encuestadas, aplicando el algoritmo de clasificación automática que permitió poner el acento en el sector de la industria del software, al obtener un mapa de la posición de las empresas en el conjunto a partir de sus perfiles específicos, que fueron siete (Lebart et al., 2000, p. 177). Para lograr este último objetivo se utilizó el algoritmo de clasificación automática, sustentado en el principio de medias móviles activas, en el programa SPAD.

\section{Resultados}

En el primer bloque, los resultados del análisis de los cuestionarios llevaron a identificar aspectos significativos de las empresas, a la necesidad de explorar aspectos generales del conjunto y a detenerse en algunos datos significativos respecto al año de la creación de aquellas y su número de empleados. Estos aspectos se abordan a continuación, buscando destacar lo relativo a la evolución del sector de empresas de software y su madurez, mediante cruzamientos entre tres variables clave, que son: año de creación, tamaño de las empresas (por número de

\footnotetext{
${ }^{28}$ Véase cuadro 5 del anexo estadístico.
} 
empleados) y nivel calificación de los empleados (en dos categorías). En la segunda sección del análisis multidimensional exploramos aspectos relacionados con lo que se denominó dimensión científica de las empresas (segundo bloque). Para la presentación de estos resultados utilizamos la cartografía espacial, clasificando las empresas en subgrupos por los perfiles específicos (atributos científicos, como se explicó en el párrafo anterior).

\section{Aspectos generales de la evolución de las empresas}

Los datos de la muestra sobre año de creación de las empresas, tamaño por su número de empleados y el nivel de calificación de su personal sirven para hacer una descripción muy sintética de la evolución del sector desde la década de los ochenta, en los que se estima que aparecieron las primeras empresas locales del ramo en México. El cruce de estas variables hizo posible destacar dos ejes relevantes de esta industria: la evolución reciente del sector y el grado de maduración que han logrado en su desarrollo subsecuente.

Durante los últimos 30 años el mayor crecimiento en el número de empresas tuvo lugar después del año 2000 en que se crearon 58\% de éstas; sin embargo, el cruce por décadas de 1980 a 2010 con el tamaño de empresa micro, pequeña, mediana y gran empresa de servicios, ayudó a identificar con mayor claridad la evolución experimentada por las empresas de esta industria durante el periodo (véase cuadro 2 del anexo estadístico). Se encontró que el patrón de consolidación en las empresas fundadas en la década de 1980-1990 y las fundadas en 1990-2000 y 2000-2010 fue muy similar: la participación de las microempresas representó entre 75 y $95 \%$ en los 30 años, disminuyendo considerablemente la participación de las mayores. La aparición de nuevas empresas denota que hay un gran dinamismo en el sector en la última década.

La información en cuanto al nivel de calificación se cruzó con el de tamaño de la empresa, encontrando lo siguiente: en las microempresas la participación promedio del personal consolidado es de $56 \%$, en tanto que la del no consolidado fue de $44 \%$. En las pequeñas empresas el personal consolidado es mayoría ( $75 \%$ ) y el no consolidado de $25 \%$; en las medianas empresas, la proporción de personal consolidado es de $100 \%$, mientras que en la gran empresa los porcentajes se vuelven a equiparar (véase cuadro 2 del anexo estadístico). Estos resultados invitan a pensar que un tamaño óptimo en este tipo de empresas es el mediano. 


\section{Densidad de los atributos "científicos" de la empresa}

El análisis de correspondencias múltiples y la clasificación posterior llevó a establecer cinco "subgrupos" por su identificación con las características científicas. Las agrupaciones se resumen en la grafica 1, en la cual se sitúan dentro de la misma métrica las intersecciones entre la posición de cada empresa y la posición que tienen las variables derivadas del posicionamiento de los perfiles. Lo que destaca la gráfica es que el conjunto de empresas estudiadas mantiene diferencias y semejanzas entre ellas, lo que dio lugar a los cinco subgrupos, con base en una serie de factores en común que tienen una posición diferente en el espacio de la grafica en razón de sus atributos.

En el extremo izquierdo del origen se define un subgrupo, número 3, en el que hay 16 empresas cuyas características particulares son: mantener acuerdos con instituciones de educación superior, contar con una infraestructura intermedia, vender directamente y declarar que utilizaron fondos sectoriales, lo que quiere decir que cuentan con cuatro de los siete atributos "científicos". El otro subgrupo, que está alejado del origen, es el número 1; hay 10 empresas que se caracterizan por ser las más antiguas del sector, por exportar directa e indirectamente sus servicios, por contar con una infraestructura avanzada. El subgrupo 2 se localiza en el origen y concentra a 18 empresas fundadas en su mayoría durante la década de 1991-2010 y que se caracterizan por subcontratar sus servicios; sus clientes pertenecen a la zona, tienen una infraestructura intermedia y cuentan con título de propiedad intelectual. El subgrupo 4 está formado por dos empresas, cuyo principal atributo es ser exportadores indirectos. El subgrupo 5 es el más numeroso, con 23 empresas que se caracterizan por contar con título de propiedad intelectual, con una infraestructura intermedia, por mantener acuerdos con instituciones de educación superior, vender directamente, situarse en un nivel medio de servicios con valor agregado y contar además con recursos de Prosoft.

Lo que deriva del análisis anterior es que más de la mitad de las empresas encuestadas (subgrupo 3 y 5) tienen por lo menos tres de los siete atributos “científicos" (véase gráficas 1 y 2).

Otro aspecto clave es el cruce de los atributos científicos con los ecosistemas de las cuatro ciudades. En el primer subgrupo, 50\% las empresas son del Distrito Federal, $10 \%$ de Guadalajara y $40 \%$ de Tijuana. En el segundo y tercer subgrupos, $35 \%$ de las empresas pertenecen al Distrito Federal, 38\% a Guadalajara, $18 \%$ a Tijuana y $9 \%$ a Mexicali; en tanto, en los subgrupos 4 y 5, 56\% son del Distrito Federal, 16\% de Guadalajara, 8\% de Tijuana y 20\% de Mexicali. 
Estos resultados confirman la hipótesis de que hay correspondencia entre la densidad del ecosistema y la complejidad de la empresa (estatus científico).

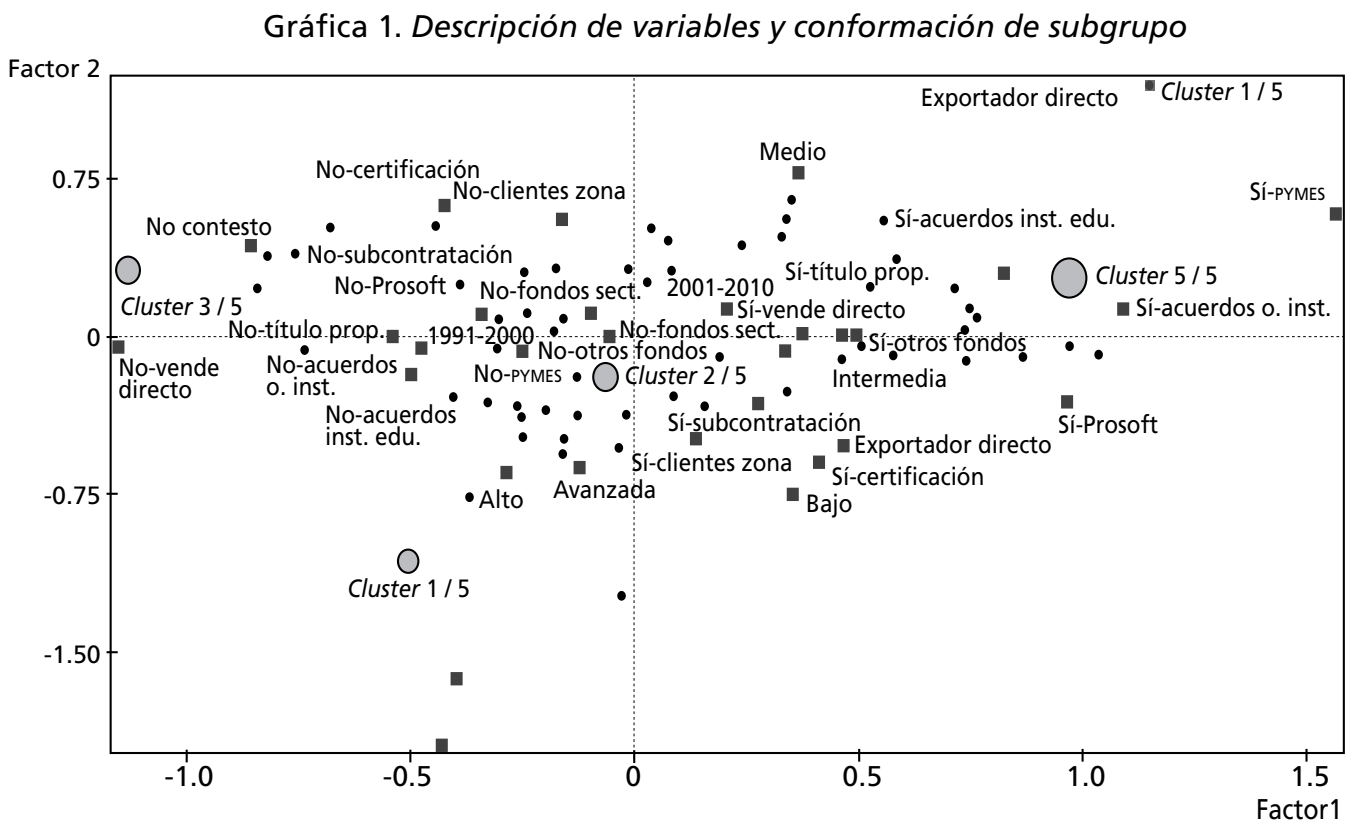

Gráfica 2. Descripción de localización de empresas en cluster

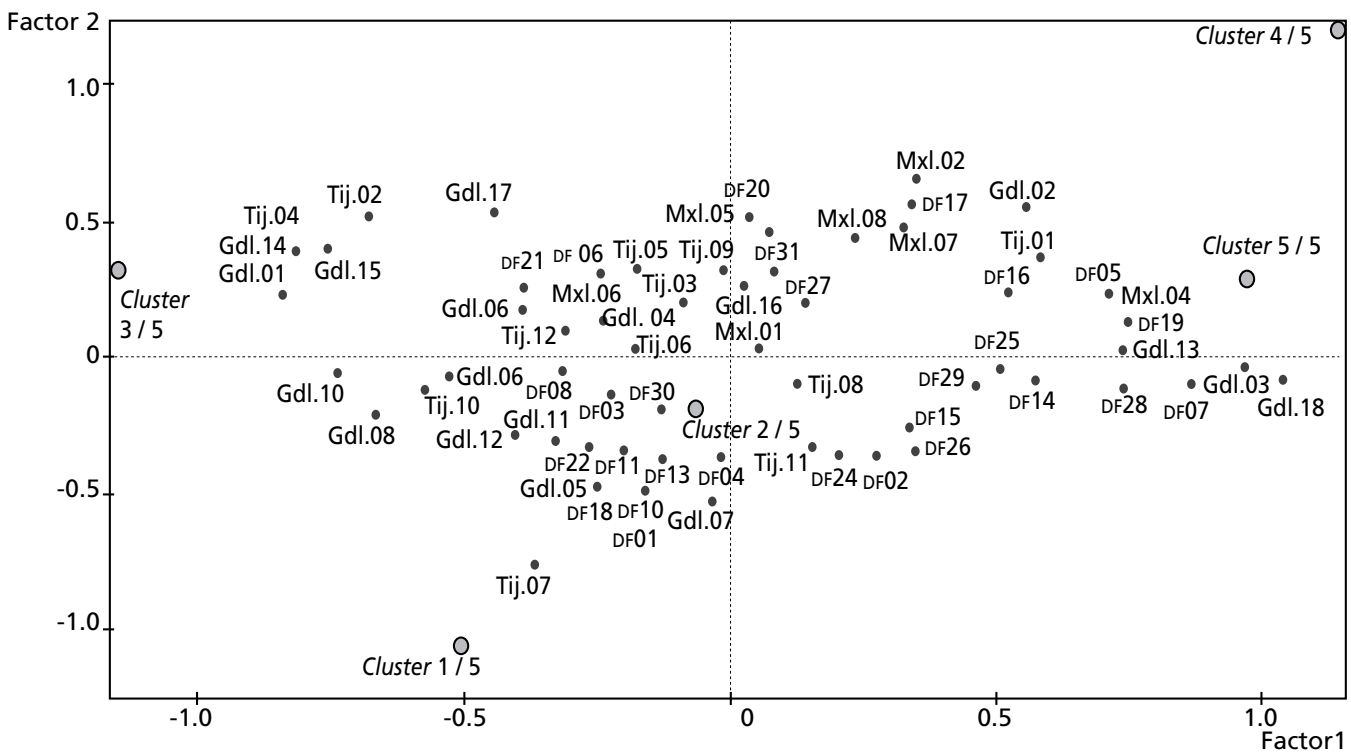




\section{CONCLUSIÓN: OPCIONES ESTRATÉGICAS PARA LOS SERVICIOS DE SOFTWARE}

Con la advertencia de que las opciones estratégicas requieren un cambio en la correlación con el poder político, es decir, que existe una diferencia decisiva entre intervenciones superficiales $v s$. profundas, vale la pena discutir brevemente el escenario actual y las posibles variantes en función de las experiencias exitosas en otros países. Tomaremos como referente algunas de las líneas dominantes del Prosoft.

Tomando como inspiración el programa brasileño, y en el marco de una filosofía posaperturista (enfoque horizontal, función de coordinador y promotor, restricción presupuestaria, apertura indiscriminada a los agentes extranjeros, etcétera), el gobierno federal propuso a inicios de 2000 un conjunto de siete líneas estratégicas para desarrollar el mercado interno, atraer capital extranjero e impulsar las exportaciones en servicios de software. La meta primordial es que para 2013 se hayan constituido en el país casi 500 empresas internacionalmente competitivas, empleando a 100 mil personas, con una producción de 5 mil millones de dólares (el monto logrado por la India en 2000). Lo anterior equivale a alcanzar el promedio mundial de $4.3 \%$ respecto del PIB.

La parte medular del programa, que tiene una base instrumental clara, radica en transferir el mercado cautivo en manos del sector público a las empresas privadas, aunque en la práctica principalmente favorece a la empresa extranjera por las razones que se explicaron previamente. Complementando lo anterior, se propuso la creación de polos de desarrollo apoyados en parques tecnológicos, en los que se insertarían las instituciones educativas. Los polos tecnológicos estarían estructurados en torno de empresas extranjeras que actuarían como pivotes. El compromiso explícito del gobierno ha consistido en conceder exenciones tributarias para que se instalen las empresas extranjeras y financiar la infraestructura de comunicaciones, además de promover el enlace con las instituciones educativas.

Siendo el programa más avanzado concebido en el gobierno federal en la década actual, presenta, sin embargo, fallas fundamentales de concepción e instrumentación que explican la falta de detonación de la industria que se esperaba en la primera etapa, es decir, hacia mediados de la década del 2000. Si se multiplicaron las empresas científicas en Guadalajara y el Distrito Federal, fue básicamente por los efectos de aglomeración, ya que la estrategia pública está desestructurada. La calidad de la gestión pública es baja porque los 
intereses industriales dominantes tienen un interés limitado en promover el aprendizaje social.

La propuesta de transferir el mercado cautivo en manos del sector público a las empresas privadas no toma en cuenta los derechos de propiedad. Los grandes usuarios públicos tienen por lo general un contrato con empresas propietarias de plataformas como Microsoft, SAP, Oracle, etcétera, de modo que esa demanda tiene que desengancharse de esa modalidad contractual para pasar a contratar proveedores locales. Un requisito para ello es naturalmente la adopción del software libre en el nivel gubernamental, como lo hizo el gobierno brasileño. La resistencia de los líderes globales es intensa, sobre todo en países como México. El programa de reserva nacional para la industria de cómputo en Brasil y la expulsión de IBM de la India son antecedentes positivos que indican una correlación favorable a los intereses endógenos que no tiene equivalente en México y tampoco se perfila en un futuro inmediato.

Según la información obtenida en las entrevistas y de fuentes periodísticas, el gobierno de Calderón empieza a optar por lo que llamamos la segunda variante: los proveedores globales genéricos. La razón es obvia: las empresas doméstico-locales, aun las científicas, no tienen capacidad para la ejecución de grandes proyectos, salvo contadas excepciones, aspecto no atendido por el Prosoft.

El enorme contrato con el IMSS concedido a Tata Consulting es un ejemplo de búsqueda de una opción frente a los propietarios de plataformas. El Prosoft no fue capaz de promover las economías de escala entre las empresas locales, lo que las dejó fuera de la iniciativa de diversificar la cartera de proveedores al sector público. Quien se prepara para contender contra los genéricos globales es Telmex, que con un spin-off con las fábricas de software, empezó centralizando sus operaciones, consolidándose después con la compra de Hildebrando.

Se advierte que lo preocupante de esta vía es que tiende a dejar fuera a las empresas doméstico-locales, aun las más avanzadas, ya que pocas de ellas tienen capacidad para ejecutar grandes proyectos. Ello representa una fragmentación del núcleo endógeno ya debilitado por las estrategias que no hacen distinciones positivas de la endogeneidad de los agentes empresariales. 


\section{ANEXO ESTADÍSTICO}

\section{Cuestionario}

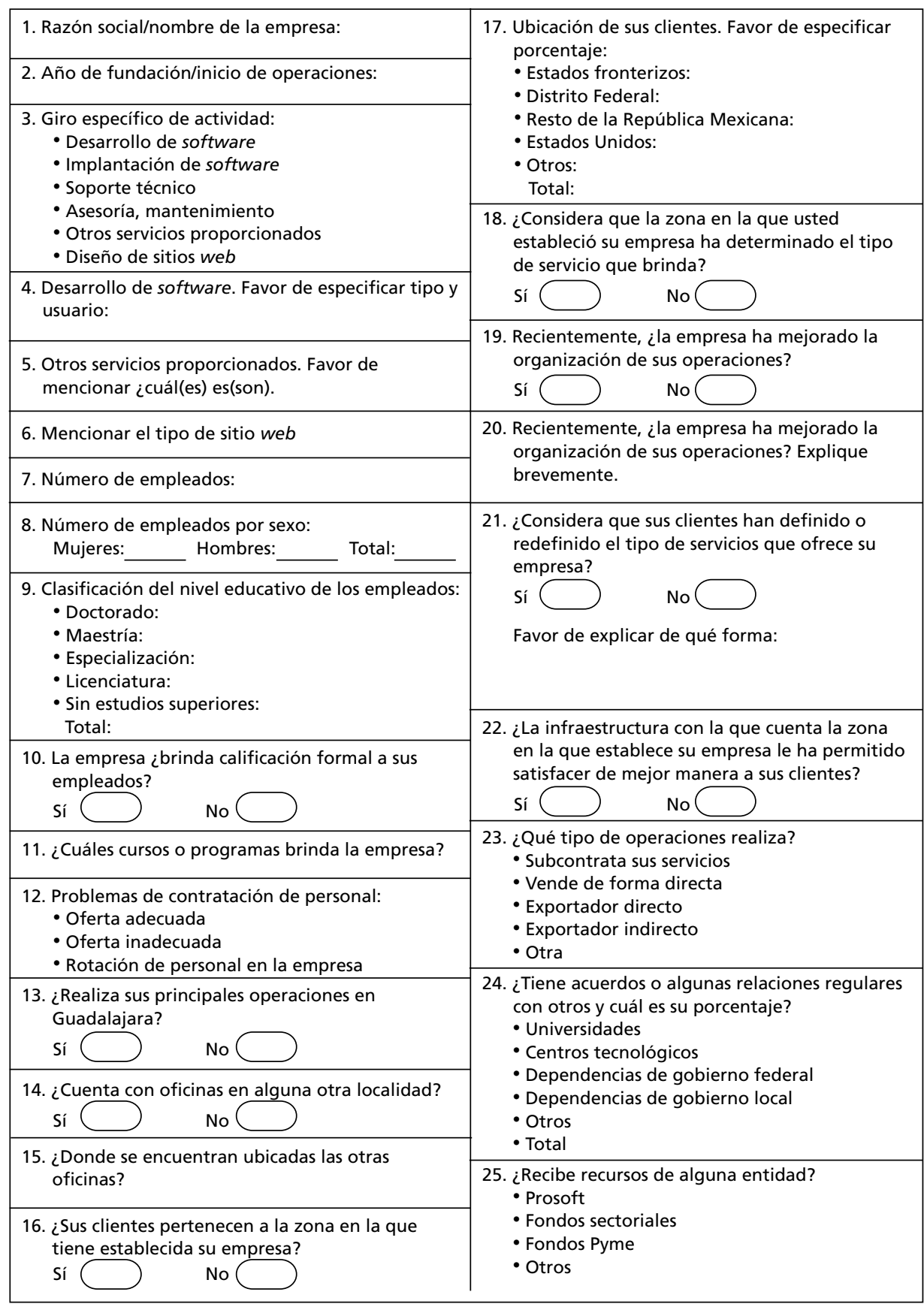




\begin{tabular}{|c|c|}
\hline \multirow{2}{*}{ 26. ¿Tiene certificación de calidad? } & 31. ¿Cuál ha sido? \\
\hline & $\begin{array}{l}\text { 32. ¿Hay efectos tangibles o evidentes en } \\
\text { productividad o calidad? }\end{array}$ \\
\hline $\begin{array}{l}\text { 27. ¿Ha solicitado algún título de propiedad } \\
\text { intelectual (derechos de autor, modelo de } \\
\text { utilidad o patente por mejoras)? }\end{array}$ & $\begin{array}{l}\text { Sí } \longrightarrow \text { No } \\
\text { ¿Cuáles? }\end{array}$ \\
\hline $\begin{array}{l}\text { 28. Describa a grandes rasgos la infraestructura de } \\
\text { la empresa (servidores, tipo de equipo de } \\
\text { cómputo, etcétera). }\end{array}$ & $\begin{array}{l}33 \text { ¿Tuvieron alguna influencia, en la productividad } \\
\text { o calidad, los clientes o proveedores? }\end{array}$ \\
\hline $\begin{array}{l}\text { 29. ¿Qué sistema operativo emplea/lenguaje de } \\
\text { programación/plataforma de desarrollo? }\end{array}$ & $\begin{array}{l}\text { 34. ¿Cómo se dio la influencia con los servicios que } \\
\text { le proporcionó la empresa? }\end{array}$ \\
\hline $\begin{array}{l}\text { 30. ¿Han efectuado alguna mejora en el servicio o } \\
\text { producto que comercializa? }\end{array}$ & $\begin{array}{l}\text { 35. Antes de los problemas económicos recientes } \\
\text { ¿cómo era su evaluación del mercado? }\end{array}$ \\
\hline
\end{tabular}

Cuadro 1. Variables y modalidades

\begin{tabular}{|c|c|c|}
\hline & & Categorías de variables $^{a}$ \\
\hline \multirow{11}{*}{$\begin{array}{l}\text { Características generales de } \\
\text { la empresa }\end{array}$} & Año de fundación & $\mathrm{N}$ \\
\hline & Número de empleados & $\mathrm{C}$ \\
\hline & Personal consolidado & $\mathrm{N}$ \\
\hline & Personal en formación & $\mathrm{N}$ \\
\hline & Fronterizos & $\mathrm{C}$ \\
\hline & Distrito Federal & $\mathrm{C}$ \\
\hline & República Mexicana & $\mathrm{C}$ \\
\hline & Estados Unidos & $\mathrm{C}$ \\
\hline & Otros & $\mathrm{C}$ \\
\hline & $\begin{array}{l}\text { Acuerdos con instituciones de } \\
\text { educación. }\end{array}$ & $\mathrm{N}$ \\
\hline & Acuerdos con otras Instituciones & $\mathrm{N}$ \\
\hline \multirow{12}{*}{$\begin{array}{l}\text { Características de sistema } \\
\text { y de organización de las } \\
\text { empresas }\end{array}$} & Prosoft & $\mathrm{N}$ \\
\hline & Fondos sectoriales & $\mathrm{N}$ \\
\hline & Fondos Pyme & $\mathrm{N}$ \\
\hline & Otros fondos & $\mathrm{N}$ \\
\hline & Certificación de calidad & $\mathrm{N}$ \\
\hline & Título de propiedad & $\mathrm{N}$ \\
\hline & Clientes de la zona & $\mathrm{N}$ \\
\hline & Subcontrata servicios & $\mathrm{N}$ \\
\hline & Vende directo & $\mathrm{N}$ \\
\hline & Exporta directo e indirecto & $\mathrm{N}$ \\
\hline & Tipo de servicio de valor agregado & $\mathrm{N}$ \\
\hline & Infraestructura de la empresa & $\mathrm{N}$ \\
\hline
\end{tabular}

${ }^{a}$ Nomenclatura: N: Nominal; C: continua.

Fuente: Elaboración propia. 
134 ECONOMÍA: TEORÍA Y PRÁCTICA • Nueva Época, número 33, julio-diciembre 2010

Cuadro 2. Evolución de las empresas ${ }^{a}$

\begin{tabular}{|cccccc|}
\hline Periodo & $\begin{array}{c}\mathbf{0 - 1 0} \\
\text { empleados }\end{array}$ & $\begin{array}{c}\mathbf{1 1 - 5 0} \\
\text { empleados }\end{array}$ & $\begin{array}{c}\mathbf{5 1 - 1 0 0} \\
\text { empleados }\end{array}$ & $\begin{array}{c}\text { 101-más } \\
\text { empleados }\end{array}$ & Total \\
\hline $1980-1990$ & $75.0 \%$ & $0.0 \%$ & $25.0 \%$ & $0.0 \%$ & $100.0 \%$ \\
$1991-2000$ & $80.0 \%$ & $12.0 \%$ & $0.0 \%$ & $8.0 \%$ & $100.0 \%$ \\
$2001-2010$ & $95.0 \%$ & $2.5 \%$ & $2.5 \%$ & $0.0 \%$ & $100.0 \%$ \\
\hline
\end{tabular}

${ }^{\text {a }}$ En los rangos de las empresas se utilizó el criterio de clasificación del INEGI para empresas de servicios.

Fuente: Elaboración propia.

Cuadro 3. Consolidación de las empresas

\begin{tabular}{|cccc|}
\hline Tamaño de empresas & Sí consolidado & No consolidado & Total \\
\hline 0 -10 empleados & $55.7 \%$ & $44.3 \%$ & $100.0 \%$ \\
$11-50$ empleados & $75.0 \%$ & $25.0 \%$ & $100.0 \%$ \\
$51-100$ empleados & $100.0 \%$ & $0.0 \%$ & $100.0 \%$ \\
$101-$ más empleados & $50.0 \%$ & $50.0 \%$ & $100.0 \%$ \\
\hline
\end{tabular}

Fuente: Elaboración propia.

Cuadro 4. Directorios de empresas de software y número de empresas que respondieron ${ }^{\mathrm{a}}$

\begin{tabular}{|l|c|c|c|c|}
\hline & Distrito Federal & Guadalajara & Tijuana & Mexicali \\
\hline Directorio & 63 & 30 & 40 & 16 \\
\hline Respondieron & 31 & 18 & 12 & 8 \\
\hline
\end{tabular}

${ }^{a}$ El directorio del Distrito Federal es el de la Asociación Mexicana de la Industria de Tecnologías de la Información (AMITI). El de Guadalajara es el del Instituto Jalisciense de Tecnologías de la Información (ljalti). El directorio de Tijuana y Mexicali es el de ITBaja.

Cuadro 5. Clasificación de los servicios de software por nivel de valor agregado

\begin{tabular}{|l|}
\hline \multicolumn{1}{|c|}{ Tipo de servicio por nivel de valor agregado } \\
\hline \multicolumn{1}{|c|}{ Alto } \\
\hline Administración de proyectos \\
\hline Customer Relationship Management (CRM) \\
\hline Enterprise Resource Planning (ERP) \\
\hline Inteligencia de negocios \\
\hline Internet \\
\hline Sistemas de seguridad \\
\hline
\end{tabular}


Cuadro 5. Clasificación de los servicios de software por nivel de valor agregado (conclusión)

\begin{tabular}{|l|}
\hline \multicolumn{1}{|c|}{ Tipo de servicio por nivel de valor agregado } \\
\hline \multicolumn{1}{|c|}{ Alto } \\
\hline Sistemas informáticos \\
\hline Desarrollo web \\
\hline Telecomunicaciones \\
\hline \\
\hline Capacitación \\
\hline Consultoría \\
\hline Desarrollo básico a la medida \\
\hline Desarrollo web \\
\hline Reingeniería de procesos \\
\hline Soluciones administrativas \\
\hline \\
\hline Cobranza especializada \\
\hline Mercadotecnia por Internet \\
\hline Software para farmacias y pequeños negocios \\
\hline Soluciones administrativas \\
\hline
\end{tabular}

\section{REFERENCIAS BIBLIOGRÁFICAS}

Amsden, Alice (2001), The Rise of the Rest: Challenges to the West from Late-Industrialization Economics, Oxford, Oxford University Press.

Arora, A., y A. Gambardella (2005), From Underdogs to Tigers: The Rise and Growth of the Software Industry in Brazil, China, India, Ireland, and Israel, Oxford University Press, Oxford.

Athreye, Suma (2005), “The Indian Software Industry”, en A. Arora, y A. Gambardella (2005).

Bátiz, José (2006), “La industria maquiladora de exportación bajo el GATT y TLCAN 19802005”, Facultad de Ciencias Sociales y Políticas, Universidad Autónoma de Baja California, campus Mexicali, tesis de licenciatura.

Bell, Martin, y K. Pavitt (1992), “Accumulating Technological Capability in Developing Countries", Annual Conference on Development Economics, Banco Mundial.

y M. Albu (1999), "Knowledge Systems and Technological Dynamism in Industrial Clusters in Developing Countries", World Development, Vol. 27, núm. 9, pp. 1715-1734. 
Bottelho, A., et al. (2005), The Brazilian Software Industry, en A. Arora, y A. Gambardella.

Breschi, Stefano, y F. Malerba (2001), "The Geography of Inovation and Economic Clustering: Some Introductory Notes", Industrial and Corporate Change, Vol. 10, núm. 4.

Bresnahan, Timothy, A. Gambardella y A. Saxenian (2001), “Old Economy Inputs for New Economy Outcomes: Clusters Formation in the New Silicon Valleys", Industrial and Corporate Change, Vol. 10, núm. 4, pp. 835-860.

Breznitz, Dan (2005), “The Israeli Software Industry”, en A. Arora, y A. Gambardella (2005).

Cadena Productiva de la Electrónica A.C. (Cadalec), www.Cadalec.com

Carrillo, J., y A. Hualde (1997), "Maquiladoras de tercera generación. El caso de DelphiGeneral Motors", Comercio Exterior, Vol. 47, núm. 9, septiembre.

Clavijo, Fernando, y Susana Valdivieso (1994), "La política industrial en México 19881994", en F. Clavijo, y J. Casar (comps.), La industria mexicana en el mercado mundial, México, Fondo de Cultura Económica.

Dabat, Alejandro (2002), "Globalización, capitalismo actual y nueva configuración espacial del mundo", en Basave, J., et al. (coords.), Globalización y alternativas incluyentes para el siglo XXI, México, UNAM, UAM-I y Miguel Ángel Porrúa,

, S. Ordóñez y M. A. Rivera R. (2005), "La reestructuración del cluster electrónico de Guadalajara (México) y el nuevo aprendizaje tecnológico", Problemas del Desarrollo, Vol. 36, núm. 143, octubre-diciembre.

—, M. A. Rivera Ríos, y S. Sztulwark (2007), "Rentas económicas en el marco de la globalización: desarrollo y aprendizaje. Implicaciones para América Latina", en M. A. Dabat, y S. Sztulwark, Problemas del desarrollo, Vol. 38, núm. 151, octubre-diciembre.

y S. Ordoñez (2009), Revolución informática, nuevo ciclo industrial e industria electrónica de exportación, México, UNAM-Juan Pablos.

Dussel, E. (1998), La subcontratación como proceso de aprendizaje: el caso de la electrónica en Jalisco (México) en la década del noventa, Santiago de Chile, CEPAL.

Ernst, D. (2010), "Innovación Offshoring en Asia: Causas de fondo de su ascenso e implicaciones de política”, en María de los Ángeles Pozas, M. Rivera Ríos y A. Dabat (coords.), Redes globales de producción, rentas económicas y estrategias de desarrollo: La situación de América Latina, Centro de Estudios Sociológicos, Colmex, México.

Estrella, Gabriel, y A. Ranfla (2007), Educación, crecimiento y desarrollo en Baja California, México, Miguel A. Porrúa. 
Evans, P. (1995), Embedded Autonomy. State and Industrial Transformation, Princeton, Princeton University Press.

Fajnzylber, Fernando (1983), La industrialización trunca de América Latina, Nueva Imagen, México.

Fernández, Ramiro, y José Ignacio Vigil (2007), “Clusters y desarrollo territorial. Revisión teórica y desafíos metodológicos para América Latina”, Economía, Sociedad y Territorio, Vol. 6, núm. 24.

- (2008), "Cluster: desde los escenarios centrales a su arribo en Latinoamérica, 'fallas de origen', reformulaciones teóricas y desafíos metodológicos", en Fernández, R, y José Vigil (coords.), Cluster y desarrollo regional en América Lati$n a$, Buenos Aires, Universidad Nacional del Litoral-Facultad de Ciencias Económicas-Miño y Dávila,.

- (2010), "Desarrollo regional bajo transformaciones trans-escalares. ¿Por qué y cómo recuperar el Estado nacional", en Ramiro Fernández, y Carlos Brandao (comps.), Escalas y políticas del desarrollo regional. Desafios para América Latina, Buenos Aires, Universidad Nacional del Litoral y Mino Dávila Editores.

Foro Científico y Consultivo (2006), "Diagnóstico de la política científica, tecnológica y de fomento a la innovación (2000-2006)", FССут, México.

Hall, David, y D. Soskice (2001), Varieties of Capitalism: the Institutional Foundations of Comparative Advantage, Oxford, Oxford University Press.

Held, D., A. McGrew, D. Goldbaltt, y J. Perraton (2000), "Global Transformation: Politics, Economic and Culture", Polity Press, Stanford University Press, Stanford.

Hikino, T., y A. Amsden (1998), "Staying Behind, Stumbling Back, Sneaking up, Soaring Ahead: Late Industrialization in Historical Perspective", P. O'Brien (comp.), Industrialisation. Critical Perspective on the World Economy, Londres, Roultledge.

Hoff, Carla, y Joseph Stiglitz (2004), "La teoría económica moderna y el desarrollo", en Meier, G., y J. Stiglitz (comps.), Fronteras de la economía del desarrollo. El futuro en perspectiva histórica, México, Banco Mundial-Alfaomega.

Hualde, A., y P. Mochi (2008), “¿Una apuesta estratégica por la industria del software?”, Comercio Exterior, Vol. 58, núm. 5, mayo.

— y R. Gomís (2009), Pymes de software en la frontera norte de México. Desarrollo empresarial y construcción institucional de un software, México, Colegio de la Frontera Norte.

Kohli, Atul (2004), State-Directed Development. Political Power and Industrialization in the Global Periphery, Cambridge, Cambridge University Press.

Krugman, Paul (1998), "What is New about New Economic Geography?", Review of Economic Policy, Oxford, Vol. 12, núm. 2, pp. 1-17. 
Lara Rivero, Arturo (2007), "Instituciones, empresas, mercado y capacidades de aprendizaje: el programa de investigación”, en R. A. Lara (coord.), Coevolución de empresas, maquiladoras, instituciones y regiones: una nueva interpretación, México, UAM-Xochimilco, Hadita y M. A. Porrúa.

Lebart, Ludovic, Alain Morineau, y Marie Piron (2000), Statistique exploratoire multidimensionnelle, París, Dunod.

Messerschmitt, D., y C. Szyperski (2003), Software Ecosystem, Understanding an Indispensable Technology and Industry, Cambridge, The MITT Press.

Mochi, Prudencio (2006), La industria del software en México en el contexto latinoamericano y mundial, CRIM-UNAM.

y Alfredo Hualde (2007), "La industria del software en México", mimeografiado.

Montiel, Víctor (2009), “El ascenso tecnoeconómico dentro de la red de una producción global, a partir de la acumulación del conocimiento. Caso práctico: la industria de la informática en Guadalajara, 2002-2008”, México, Facultad de EconomíaUNAM, tesis de licenciatura.

Morineau, Alain, y Stéphane Morin (2000), Pratique du traitement des enquêtes, París, Decisia.

Moscoloni, Nora (2005), "Nube de datos: Métodos para analizar la complejidad", Argentina, Universidad Nacional de Rosario.

Mowery, David (1999), “The Computer Software Industry”, en D. Mowery, y R. Nelson, Sources of Industrial Leadership. Studies of Seven Industries, Cambridge, Cambridge University Press.

North, Douglas (1984), Estructura y cambio en la historia económica, Madrid, Alianza Universidad.

_ , J. Wallis y B. Weingast (2009), Violence and Social Order. A Conceptual Framework for Interpreting Recorded Human History, Cambridge, Cambridge University Press.

Palacios Lara, José Juan (2003), “¿La industria electrónica en Jalisco. Aglomeración desarticulada o complejo industrial integrado?", en E. Dussel, J. Palacios, y G. Woo (coords.), La industria electrónica en México: problemática, perspectivas y propuestas, México, Universidad de Guadalajara.

Porter, Michael (1991), La ventaja competitiva de las naciones, Buenos Aires, Ed. Vergara. Rivera Ríos, Miguel Ángel (2009a), Desarrollo económico y cambio institucional. El atraso económico y el desarrollo tardio en perspectiva histórica, México, UNAM-Juan Pablos.

- (2009b), "Cambio tecnológico, complejidad e instituciones", Problemas del Desarrollo, Vol. 40, núm. 157, abril-junio. 
Sands, Anita (2005), "The Irish Software Industry”, en A. Arora, y A. Gambardella.

Saxenian, Anna-Lee, y J-Yuh Hsu (2001), "The Silicon-Valley-Hsinchu Connection: Technical Communities and Industrial Upgrading", Industrial and Corporate Change, Vol. 10, núm. 4.

Schmitz, Hubert (1999), "Collective Efficiency and Increasing Returns", Cambridge Journal of Economics, Vol. 23.

Scott, Allen (1998), Regions and the World Economy. The Coming Shape of Global Production, Competition and Political Order, Oxford, Oxford University Press.

—, J. Agnew, E. Soja, y M. Storper (2001), "Global City-Regions, en Scott, A. (comps.), Global City-Regions, Oxford, Oxford University Press.

Secretaría de Economía (s/f), Programa para el Desarrollo de la Industria del Software.

SPAD-DECISIA (2003), Centre International de Statistique et d'Informatique Appliquées, París.

Storper, Michael (1997), The Regional World. Territorial Development in a Global Economy, Nueva York, The Guilford Press.

Tschang, T., y L. Xue (2005), The Chinese Software Industry, en A. Arora, y A. Gambardella.

Vázquez Barquero, A. (1999), Desarrollo, redes e innovación, Madrid, Pirámide.

Wilkie, James, y Ray Michael (2004), "Un método proporcional para estimar la brecha del PIB entre Estados Unidos y América Latina”, en A. Dabat, M. Rivera R., y J. Wilkie (comps.), Globalización y cambio tecnológico. México en el nuevo ciclo industrial mundial, México, Universidad de Guadalajara, UNAM, UCLA-Program on Mexico, PROFMEX, Juan Pablos Editor.

WITSA (World Information Technology and Service Alliance) (2006-2008) Digital Planet, The Global Information Economy. 